\title{
Reviewing subduction initiation and the origin of plate tectonics: What do we learn from present-day Earth?
}

\author{
Gang Lu* , Liang Zhao, Ling Chen, Bo Wan, and FuYuan Wu \\ State Key Laboratory of Lithospheric Evolution, Institute of Geology and Geophysics, Chinese Academy of Sciences, Beijing 100029, China
}

Key Points:

- We raise a "paradox of the first SI", a situation that appears to require existing subduction before the start of the first subduction, and review state-of-the-art SI models with a focus on evaluating their suitability in explaining the onset of plate tectonics.

- We re-investigate plate driving mechanisms and conclude that mantle drag may be more important than previously thought, which may be the missing driving force that can resolve the "paradox of the first SI".

- We propose a composite driving mechanism, one that is compatible with present-day Earth and may also be applicable to broader geodynamic settings.

Citation: Lu, G., Zhao, L., Chen, L., Wan, B. and Wu, F. Y. (2021). Reviewing subduction initiation and the origin of plate tectonics: What do we learn from present-day Earth?. Earth Planet. Phys., 5(2), 123-140. http://doi.org/10.26464/epp2021014

\begin{abstract}
The theory of plate tectonics came together in the 1960s, achieving wide acceptance after 1968. Since then it has been the most successful framework for investigations of Earth's evolution. Subduction of the oceanic lithosphere, as the engine that drives plate tectonics, has played a key role in the theory. However, one of the biggest unanswered questions in Earth science is how the first subduction was initiated, and hence how plate tectonics began. The main challenge is how the strong lithosphere could break and bend if plate tectonics-related weakness and slab-pull force were both absent. In this work we review state-of-the-art subduction initiation (SI) models with a focus on their prerequisites and related driving mechanisms. We note that the plume-lithosphere-interaction and mantleconvection models do not rely on the operation of existing plate tectonics and thus may be capable of explaining the first SI. Reinvestigation of plate-driving mechanisms reveals that mantle drag may be the missing driving force for surface plates, capable of triggering initiation of the first subduction. We propose a composite driving mechanism, suggesting that plate tectonics may be driven by both subducting slabs and convection currents in the mantle. We also discuss and try to answer the following question: Why has plate tectonics been observed only on Earth?
\end{abstract}

Keywords: subduction initiation; plate tectonics; mantle convection; driving force; mantle drag

\section{Introduction}

Earth, whose oceanic plates are formed at mid-ocean ridges and recycled into deep mantle at subduction zones, is the only planet in our solar system known to have active plate tectonics. The fact that subducted oceanic plates provide major forces to drive Earth's plate tectonics makes subduction a defining characteristic of plate tectonics. However, explaining initiation of the first subduction (subduction initiation, SI), a plausible starting point of today's plate tectonics, remains one of the key challenges in Earth sciences (Bercovici, 2003; Gerya, 2011; van Hunen and Moyen, 2012; Bercovici et al., 2015). The main difficulty is to reconcile the great plate strength without plate tectonics-related fracture zones and the weak driving force owing to the lack of slab pull prior to the start of plate tectonics.

Studies over recent decades have greatly advanced our under-

Correspondence to: G. Lu, Ivgang@mail.iggcas.ac.cn

Received 18 OCT 2020; Accepted 11 DEC 2020.

Accepted article online 27 JAN 2021.

C 2021 by Earth and Planetary Physics. standing of how subduction could be initiated at various geological settings, knowledge that has been summarized intensively in a number of earlier reviews (Stern, 2004; Gerya, 2011; Korenaga, 2013; Zheng and Chen, 2016; Coltice et al., 2017; Stern and Gerya, 2018; Crameri et al., 2019). Yet, the start of the first subduction remains enigmatic, largely due to incomplete understanding of driving forces. While there is no doubt that subducting slabs are the primary drivers of modern plate tectonics, the assumption that subduction has always been dominating leads immediately to difficulty in explaining the first SI: a subducting slab is required before the start of the first subduction.

In this paper we review state-of-the-art SI models and evaluate whether they require prior operation of plate tectonics. We choose to focus on the relationship between plate strength and driving mechanism during SI. The structure of this review is as follows: We begin in Section 2 by summarizing key characteristics of Earth's present-day plate tectonics and its driving mechanism. In Section 3 we outline key stages of $\mathrm{SI}$, review representive resistance forces, and raise the paradox of the first SI. We present in Section 4 a classification of SI models based on their driving-force 
and plate-rupture mechanisms, which helps us to evaluate whether they could help explain the first SI. Then in Section 5 we discuss the nature of mantle drag force and propose a composite driving mechanism for plate tectonics that includes mantle drag, which may provide the missing driving force that is needed to explain the first subduction initiation. We further discuss why plate tectonics is rare on terrestrial planets. Our last section is a summary with some consideration for future research directions.

\section{Plate Tectonics on Earth}

The plate tectonics theory states that Earth's surface is divided into several rigid blocks (plates) with most of the deformation concentrated at their boundaries (Kreemer et al., 2014) (Figure 1). The relative motion of these plates leads to various types of plate boundaries, i.e., divergent, convergent, or transform boundaries. Subduction at convergent boundaries, which brings surface materials back to the deep mantle, is a key element of plate tectonics that differs from mantle convection regimes observed on other planets. Mantle convection on most other terrestrial planets and moons is probably in stagnant lid regime: the strong stagnant lid has remained on the surface for billions of years while the underlying mantle has been vigorously convective (Korenaga, 2013; Stern et al., 2018). Venus's dynamic evolution is believed to be characterized by the episodic style of mantle convection: longlasting stagnant-lid periods are interrupted by short, dramatic periods of global overturns (Moresi and Solomatov, 1998; Reese et al., 1999; Armann and Tackley, 2012; Uppalapati et al., 2020).

It has been well established from geodynamic modeling that stagnant-lid convection is likely the dominant mode for silicate planets, due to the strongly temperature-dependent viscosity of rocks (Moresi and Solomatov, 1995, 1998). This prediction, together with observations confirming the prevalence of stagnant-lid convection on silicate planets, suggests that Earth might have evolved through a stagnant-lid phase before its current plate-tectonics phase (Sleep, 2000; Stern, 2007), although some authors suggest that a variant squishy-lid regime was present before the start of plate tectonics (Johnson et al., 2014; Rozel et al., 2017; Lourenço et al., 2020). Therefore, an understanding of the transition from stagnant-lid convection to plate-tectonics convection, i.e. the initiation of the first subduction, is crucial.

Today, there is little doubt that plates are powered mainly by subducted slabs and opposed by viscous resistance of the mantle (Forsyth and Uyeda, 1975; Lithgow-Bertelloni and Silver, 1998; Stern, 2004; Faccenna et al., 2012). The correlation between plate speed and length of attached trench relative to plate circumference (Figure 2a) is one of the strongest indications of the importance of subduction for driving plates (Forsyth and Uyeda, 1975). The slabrelated driving forces, a combination of "slab pull" and "slab suction", provide $\sim 90 \%$ of total driving force (Conrad and LithgowBertelloni, 2004), although there are alternative views on the relative importance between slab pull and slab suction (Stadler et al., 2010; Becker and Faccenna, 2011; Ghosh and Holt, 2012; Faccenna et al., 2013) (Figure 2b). "Slab pull" is a negative buoyancy force induced from the dense subducting slab that is directly attached to the surface plate, given by $\sim 3.2 \times 10^{13} \mathrm{~N} / \mathrm{m}$ (Turcotte and Schubert, 2002), while "slab suction" arises from mantle flow caused by detached sinking slabs (Conrad and Lithgow-Bertelloni, 2004). "Ridge push", which arises from the topographic gradient of oceanic plates that results from thermal thickening, provides about $10 \%$ of the driving force $\left(\sim 3.9 \times 10^{12} \mathrm{~N} / \mathrm{m}\right)$ (Turcotte and Schubert, 2002). Additional driving forces for mature subduction zones come from net effects of phase changes during subduction, such as eclogitization from oceanic crust and the shallower phase transition from olivine to wadsleyite in the cold slab at a depth of 410 km (Billen, 2008; van Hunen and Moyen, 2012). However, these forces may not be important during subduction initiation, when the slab is shallow. Lithospheric basal shear, which results

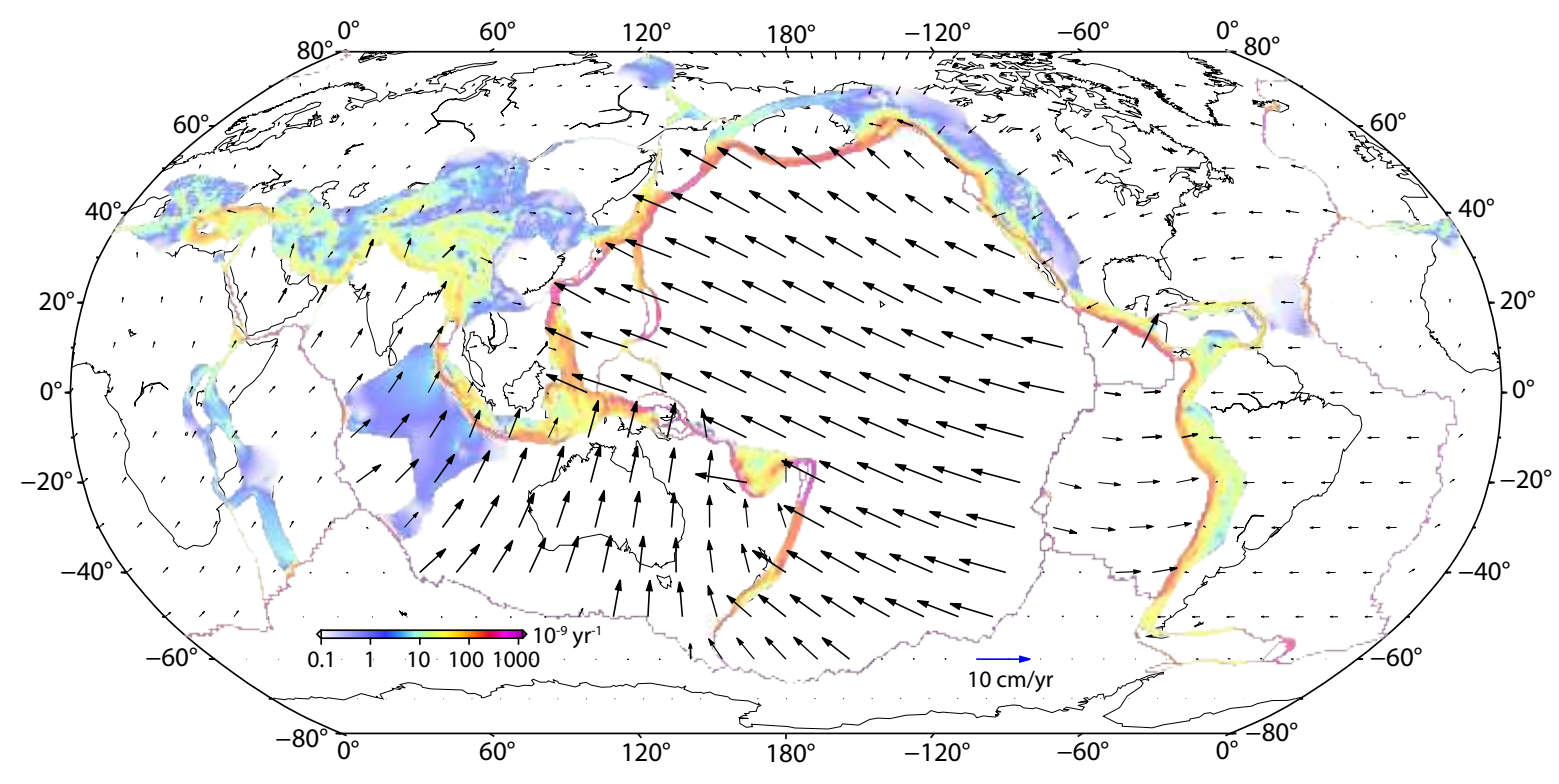

Figure 1. Present-day tectonic plates and corresponding plate motions. Colors show distribution of second invariant of strain rate that is concentrated at plate boundaries. The interior of plates (white) has little deformation, indicating the rigidity of plates. Arrows indicate plate velocities (Kreemer, 2009). Note that subducting slabs typically move faster than overriding plates. Modified from (Kreemer et al., 2014). 
from relative motion between plates and the underlying mantle, is considered either as a resisting force (Billen, 2008; van Hunen and Moyen, 2012) or to be negligible due to the presence of sublithospheric low-viscosity asthenosphere (Forsyth and Uyeda, 1975; Chapple and Tullis, 1977; Mueller and Phillips, 1991). It is hence generally accepted that Earth's plate tectonics today is a slab-driven system. In recognition of the importance of slab driving, some authors have suggested that Earth's geodynamic regime may be described as "subduction tectonics" instead of "plate tectonics" (Anderson, 2001; Stern, 2004, 2007; Stern and Gerya, 2018; Chen L et al., 2020).
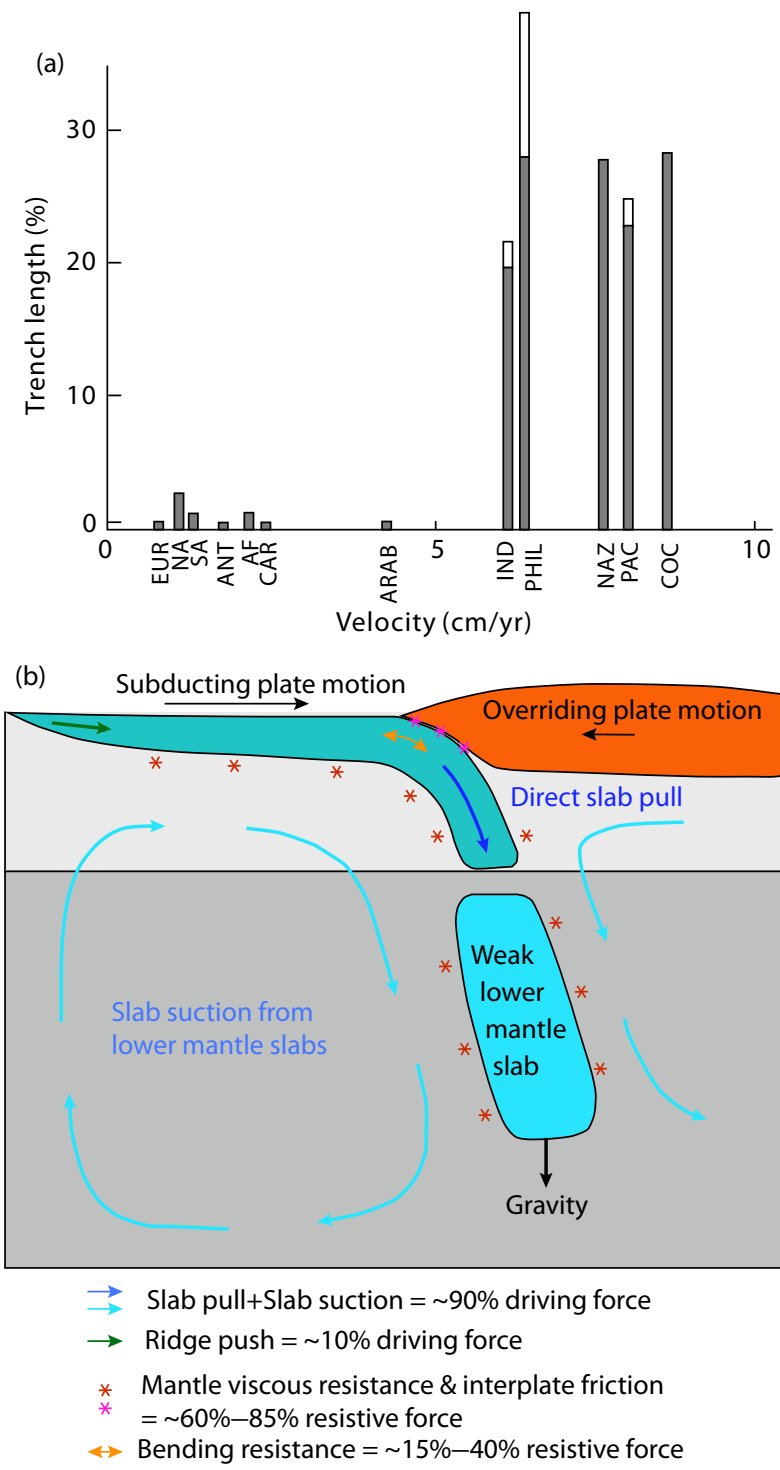

Figure 2. Driving mechanism of present-day plate tectonics. (a) Velocity-trench length relationship. Plates with larger trench length move at higher velocities. Modified from (Forsyth and Uyeda, 1975). (b) Schematic diagram showing major driving and resistance forces. The major ( 90\%) driving force comes from direct pull of attached slab and indirect suction from detached slab. Ridge push contributes a small fraction $(\sim 10 \%)$ of driving force. Resisting forces include slab bending resistance, interplate friction, and mantle viscous shear. Modified from (Conrad and Lithgow-Bertelloni, 2004; Stern, 2007).

\section{Subduction Initiation}

\subsection{Stages of SI}

Subduction initiation refers to the infancy stage before the establishment of mature subduction zones driven by the sinking of slabs. It has been suggested that two forces must initially be overcome to make a subduction zone self-sustaining (Gurnis et al., 2004): fault friction and plate bending. Following Gurnis et al. (2004), in considering the first SI, we propose that the whole time span of an SI can be generalized into four stages (Figure 3): 1) a single plate as the initial state, 2 ) plate rupture and formation of a lithospheric-scale shear zone, 3) under-thrusting of one plate beneath the other, and 4) the lower plate becoming deep enough that slab pull makes the process self-sustaining. The inclusion of Stage 1 does not mean that all subduction zones have to experience the transition from Stage 1 to Stage 2. For example, an SI due to inversion of a detachment/transform fault (Baes et al., 2011; Maffione et al., 2015) begins with the presence of two separate plates and thus experiences only Stages $2-4$. However, initiation of the first subduction has to break, in Stage 1, the initial stagnant lid. Once a first subduction has been initiated, the slab-driven mechanism can take over and dominate the operation of plate tectonics. In this view, the question of how plate tectonics started on Earth is equivalent to asking how the first subduction zone was initiated.

\subsection{Plate Strength}

Any newly initiated subduction zone must overcome an initial mechanical resistance before it becomes self-sustaining. Major

(a) Stage 1: Single plate

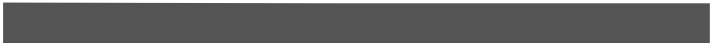

(b) Stage 2: Plate rupture

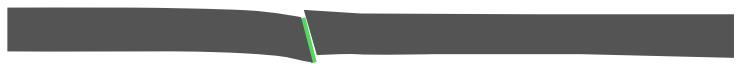

(c) Stage 3: Under-thrust

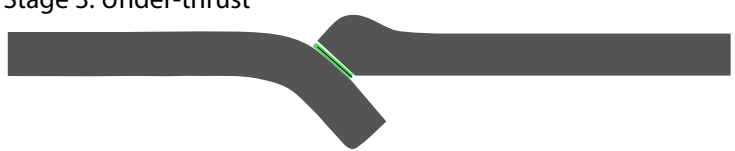

(d) Stage 4: Self-sustaining

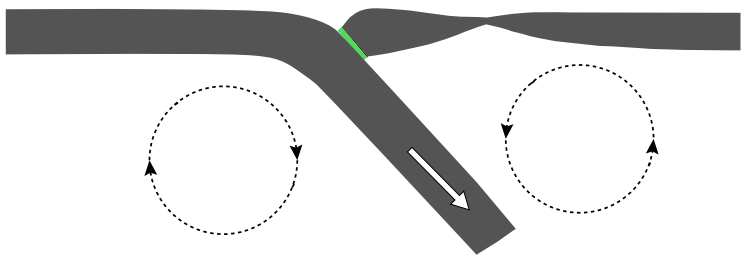

Figure 3. Generalized stages of subduction initiation. The whole time span of subduction initiation includes (a) initially a single plate (Stage 1), (b) nucleation of shear zone and plate rupture (Stage 2), (c) under-thrusting of one plate beneath another (Stage 3), and (d) establishment of self-sustaining subduction (Stage 4). In some cases, subduction initiation occurs at existing weak zones, thus involving only Stages 2-4. Modified from (Gurnis et al., 2004). 
resistance forces related to SI include (McKenzie, 1977; Mueller and Phillips, 1991; Gurnis et al., 2004) shear resistance at the (virtual) fault plane (Figure 3, Stage 2) and the bending stress when the slab evolves to larger dipping angle during under-thrusting (Figure 3, Stage 3). The shear strength of the lithosphere is best represented by the yield strength envelope (YSE) (Goetze and Evans, 1979), which is constrained by brittle failure in the shallow part and by viscous strength at greater depths where temperatures are higher. The transition from plastic to viscous deformation is often called the brittle-ductile transition (BDT). In the brittle domain, the strength of the lithosphere is limited by brittle (plastic) failure (Byerlee, 1978), which occurs following Mohr-Coulomb failure criterion (Figure 4a):

$$
\tau=C+\sigma_{\mathrm{n}} \tan \phi,
$$

where $\tau$ is the shear stress, $\sigma_{\mathrm{n}}$ the normal stress, $\phi$ the angle of internal friction, $C$ the cohesion. For dry rocks, $\phi$ is typically $30^{\circ}$. In numerical models, the Mohr-Coulomb failure criterion is often expressed in its smooth version, the Drucker-Prager criterion, as (Buiter et al., 2016) (Figure 4a):

$$
\sigma_{2 \mathrm{nd}}=\sigma_{y}=C \cos \phi+P \sin \phi,
$$

where $P$ is the total pressure (mean stress), and $\sigma_{y}$ the effective shear stress determined by the second invariant of the deviatoric stress tensor $\left(\sigma_{2 n d}=\sqrt{\frac{1}{2} \sigma_{i j}^{\prime} \sigma_{i j}^{\prime}}\right)$. For typical horizontal extension or
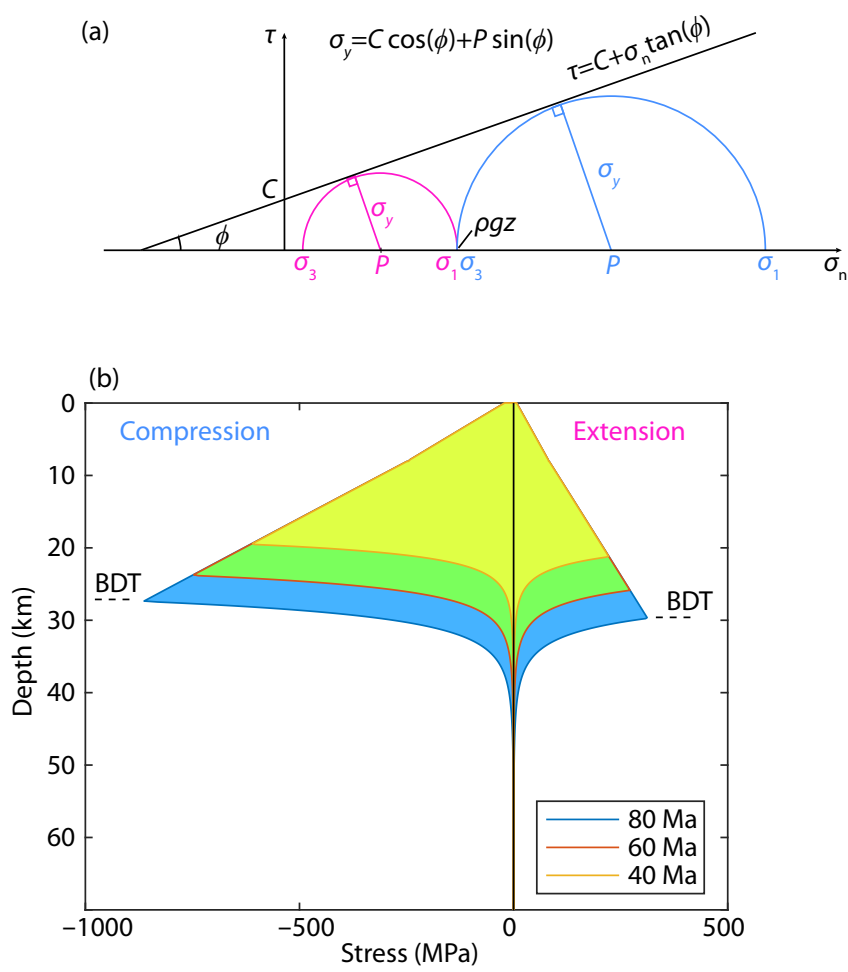

compression conditions, the yield stress is directly linked to lithostatic stress ( $\rho g z)$ (Figure 4a). The yield stress under extension can be expresses as

$$
\sigma_{y}=\frac{\rho g z \sin \phi+C \cos \phi}{1+\sin \phi}
$$

while under compression the yield stress is

$$
\sigma_{y}=\frac{\rho g z \sin \phi+C \cos \phi}{1-\sin \phi} \text {. }
$$

Note that the plate is significantly stronger under compression than extension. Taking cohesionless dry rocks for example $(\phi=$ $\left.30^{\circ}, C=0\right)$, the yield stress under extension is one-third of the yield stress under compression.

When fluid pore pressure $\left(P_{\mathrm{f}}\right)$ is present, the yield stress may be reduced due to the reduction of confining pressure, such that (e.g., Ranalli, 1995; Sibson and Rowland, 2003)

$$
\sigma_{y}=C \cos \phi+\left(P-P_{\mathrm{f}}\right) \sin \phi,
$$

which may be further simplified as (e.g., Gerya et al., 2008):

$$
\sigma_{y}=C \cos \phi_{\text {eff }}+P \sin \phi_{\text {eff }}
$$

where $\phi_{\text {eff }}$ is the effective frictional angle, $\sin \phi_{\text {eff }}=\sin \phi\left(1-\frac{P_{f}}{P}\right)$. Hydrostatic pore pressure condition with $P_{f} / P \sim 0.4$ (Sibson and

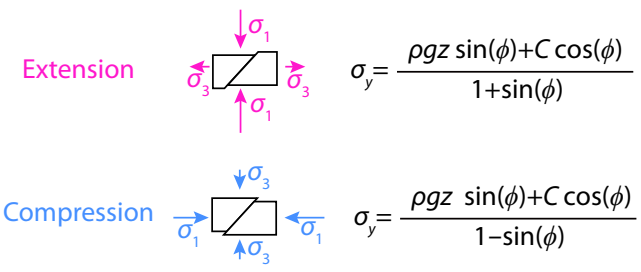

(c)
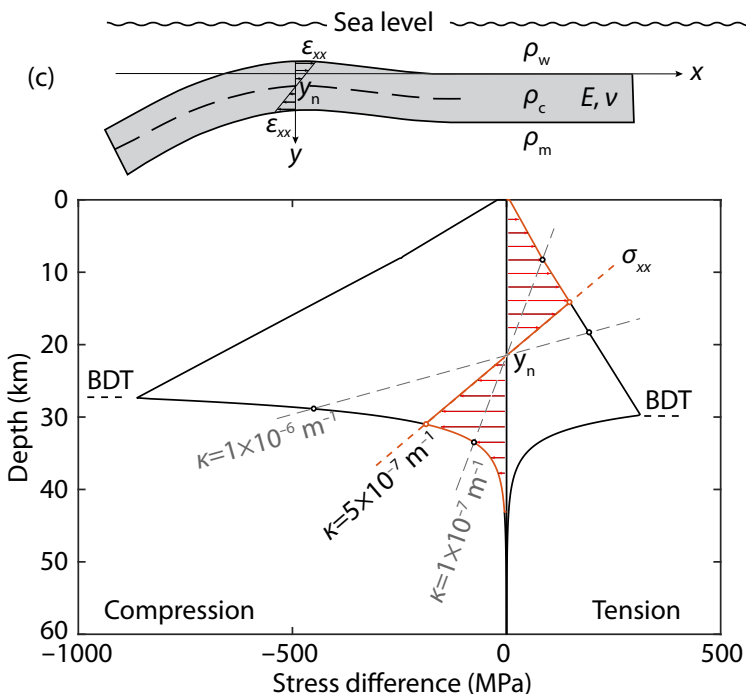

Figure 4. Strength of oceanic lithosphere. (a) Left: Mohr circle diagram of principal stresses along the Byelee's yield surface. $\sigma_{1}$ and $\sigma_{3}$ are maximum and minimum (compressional) principal stresses, respectively. $P$ is dynamic pressure. $\sigma_{y}$ is yield stress. Right: configuration of principal stresses under compression or extension and corresponding yield stresses. Note $\sigma_{1}=\rho g z$ (lithostatic pressure) for extension whereas $\sigma_{3}=\rho g z$ for compression. (b) Yield stress envelope (YSE), or shear strength, of an oceanic plate with various thermal ages. Assumed background strain rate is $10^{-15} \mathrm{~s}^{-1}$. Note that the yield stress under compression is $2-3$ times larger than under extension. BDT: brittle-ductile transition. (c) Bending strength of a subducting slab, which is linked to the shear strength. Modified from (Watts and Burov, 2003). 
Rowland, 2003) leads to an effective friction angle of $17^{\circ}$.

Figure $4 \mathrm{~b}$ illustrates a typical YSE for an oceanic lithosphere with different thermal ages assuming a dry olivine rheology and a background strain rate of $10^{-15} \mathrm{~s}^{-1}$. The integral of the YSE indicates the force required to rupture a plate. For a thermal age of $40 \mathrm{Ma}$, the force required to induce compressional failure is on the order of $10^{13} \mathrm{~N} / \mathrm{m}$, which is on the same order as slab pull (Turcotte and Schubert, 2002). The strength of a plate increases rapidly with increasing thermal age. Solely according to this aspect, older lithosphere is therefore less likely to initiate new subduction (Cloetingh et al., 1982, 1989; Mueller and Phillips, 1991).

After plate rupture occurs, plate bending becomes the principal source of resistance during SI until it becomes self-sustaining (McKenzie, 1977; Gurnis et al., 2004). The bending strength may be parameterized as a bending moment that is linked to the YSE (Figure 4c) (Watts and Burov, 2003; Burov, 2011; Hunter and Watts, 2016). For a bending plate, there will be a neutral plane $\left(y=y_{n}\right)$ where there is no deformation. Apart from the neutral plane, the elastic bending stress is (Hunter and Watts, 2016):

$$
\Delta \sigma_{x x}^{\mathrm{el}}=\frac{E\left(y-y_{\mathrm{n}}\right) \kappa}{1-v^{2}}
$$

where $\kappa$ is curvature, $E$ is Young's module, and $v$ is Poisson's ratio. This elastic bending stress is then truncated by the YSE, resulting in a bending moment calculated as:

$$
M=\int_{0}^{T_{m}} \Delta \sigma_{x x}\left(y-y_{n}\right) d y,
$$

where $T_{\mathrm{m}}$ is the mechanical thickness, defined as the depth at which the yield strength falls below 1 per cent of the overburden pressure (Hunter and Watts, 2016). The equation shows that the bending moment depends on the shear strength and the curvature of the plate. By applying a force equilibrium analysis, Buffett (2006) further estimated that an equivalent bending force can be approximated as:

$$
F_{\mathrm{b}}=-\frac{2}{3}\left(\frac{H}{R_{\min }}\right)^{3} \eta u_{0}
$$

where $H$ is plate thickness, $\eta$ is the effective viscosity of the bending lithosphere, $u_{0}$ is subduction convergence velocity, and $R_{\min }$ is the minimum radius of curvature of the bending slab. The scaling law of bending force is further verified to be proportional to $\left(\frac{H}{L_{\mathrm{b}}}\right)^{3} \eta u_{0}$ by systematic 2-D (Ribe, 2010) and 3-D (Li and Ribe, 2012) analysis and modeling, where $L_{b}$ is the bending length of the portion of the slab where deformation occurs primarily by bending rather than by stretching. The bending force acts like a resistance in that it opposes the motion of the downgoing plate. In modern subduction zones, the magnitude of bending forces is estimated to vary from $\sim 10^{12} \mathrm{~N} / \mathrm{m}$ (Davies, 2009; van Hunen and Moyen, 2012) to as high as $\sim 37 \%$ of the total slab pull (Buffett, 2006).

\subsection{The First SI Paradox}

It is commonly agreed that aging of plates does not by itself initiate subduction, because plates actually stiffen as they cool, due to the strong dependency of viscosity on temperature (Cloetingh et al., 1989; Mueller and Phillips, 1991). This is also evident from the fact that most Atlantic passive margins have been stable until now, although some investigators have argued that the Brazilian margin is at risk of future subduction initiation (Nikolaeva et al., 2010; Nikolaeva et al., 2011). In a recent compilation of SI databases, Crameri et al. (2020) argue that all Cenozoic SI events are known to be induced, suggesting that additional forcing is required besides the negative buoyancy of the surface plate itself. SI at intraoceanic setting is thought to be possible only if sufficiently long lithospheric weak zones exist, e.g., transform faults or oceanic fracture zones (Hall et al., 2003; Gurnis et al., 2004; Stern, 2004; Zhou X et al., 2020). Even with an initial weak zone, tectonic force is still required to bend the lithosphere until the subduction becomes self-sustaining (Hall et al., 2003; Gurnis et al., 2004). Therefore, for an initial single plate, additional driving force is required to break the lithosphere and overcome the bending resistance before a self-sustaining subduction can be established. On presentday Earth, the sinking subducted dense oceanic lithosphere provides most of the force required to drive tectonic plates (Forsyth and Uyeda, 1975). Some authors suggest that sinking slabs could generate some far-field tectonic stresses to trigger subduction at other places (Hall et al., 2003; Niu et al., 2003; Baes and Sobolev, 2017; Baes et al., 2018), which may explain SI during the Cenozoic. However, this mechanism, if other driving forces are excluded, leads to a paradox of the first SI: a subducting slab is required to initiate another subduction zone, but obviously there is no subduction zone before the first one is initiated. In the next section we review proposed SI models by examining their driving mechanisms and conditions prerequisite for, and during, an SI, with the aim of seeking a scenario that is capable of accounting plausibly for the initiation of the first subduction.

\section{Models of SI}

The initiation of subduction is a result of competition between driving force and plate strength. The key in SI models is to resolve the discrepancy between the strong plate strength and the small driving force. Many mechanisms have been proposed to explain how a surface plate might break. They all involve one or both of these two aspects: (1) an additional forcing to the plate and (2) a mechanism capable of rupturing (or weakening) the plate. It is well known that mature subduction is self-sustainingly driven by slab pull force. Therefore, in terms of their driving mechanisms, ongoing subduction zones have been classified into forced subduction and self-sustaining subduction (Gurnis et al., 2004). This has led to a similar classification of SI models (Stern, 2004): spontaneous $\mathrm{SI}$, in which the initiation process is driven purely by the negative buoyancy of the surface plate itself, and induced $\mathrm{SI}$, in which forcing external to the considered plate is required. However, in a recent SI database analysis, Crameri et al. (2020) demonstrate that all known SI events in the most recent $100 \mathrm{Ma}$ are forced; there is no known example of spontaneous SI. Therefore, we apply an alternative classification by considering whether the required forcing is internal or external to the considered model domain. Models that require forcing from outside the model, such as kinematic boundary pushing, are classified as externally driven. In contrast, those with all driving forces originated from within the model domain are considered as internally driven. In terms of the second aspect, i.e. the formation of plate weakness, 
many models either impose a prescribed weak zone (i.e. inherited weak zone) or use a low yield strength that is much smaller than at hydrostatic pore pressure condition (inherited weak plate). In contrast, in some other models, the lithosphere is initially strong and a lithospheric-scale shear zone is generated in a self-consistent manner (i.e. self-nucleated). This leads to a classification of plate weakness into two categories: inherited and self-nucleated.

Combining the two aspects above allows us to subdivide proposed SI models into the following four groups (Figure 5): (i) externally driven forcing with inherited plate weakness, (ii) extern-

Inherited plate weakness
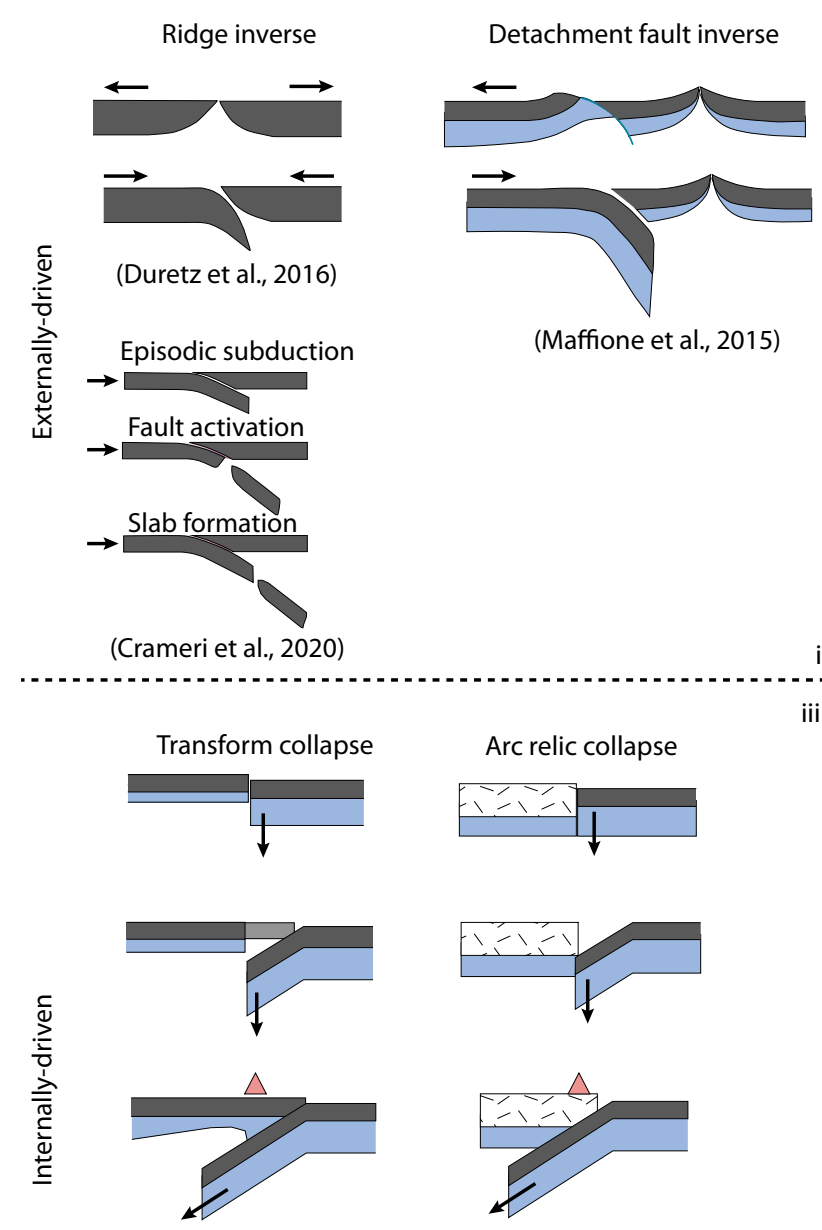

Eocene Western Pacific (e.g., Govers and Wortel, 2005) ally driven forcing with self-nucleated shear zone, (iii) internally driven forcing with inherited plate weakness, and (iv) internally driven forcing with self-nucleated shear zone. Models with external-driven forcing or inherited plate weakness typically invoke some processes that occur only during modern plate tectonics, e.g. transform faults or far-field tectonic stress from other subduction zones, which are thus not capable of explaining the first subduction initiation. After the start of plate tectonics, subduction initiation becomes less enigmatic because slab-related driving force may take over to drive and initiate subsequent subduction zones.

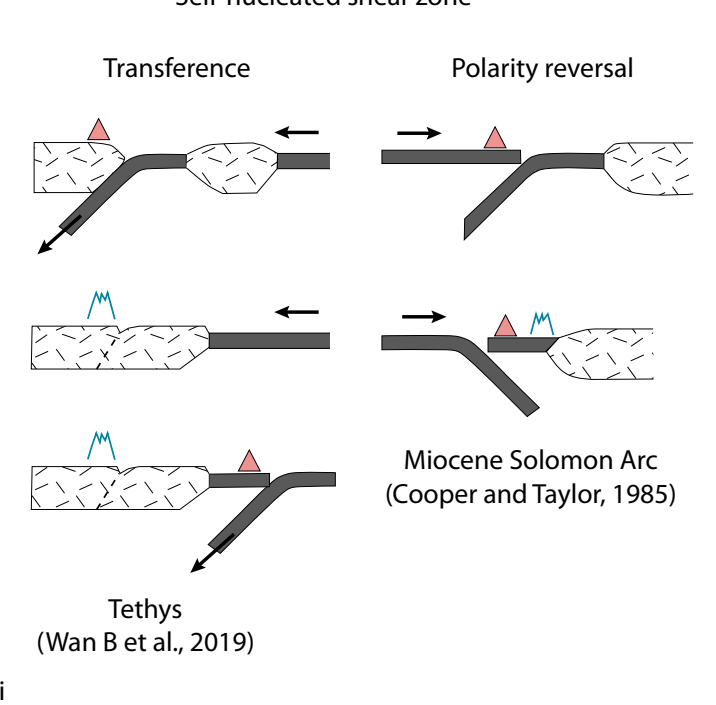
ii

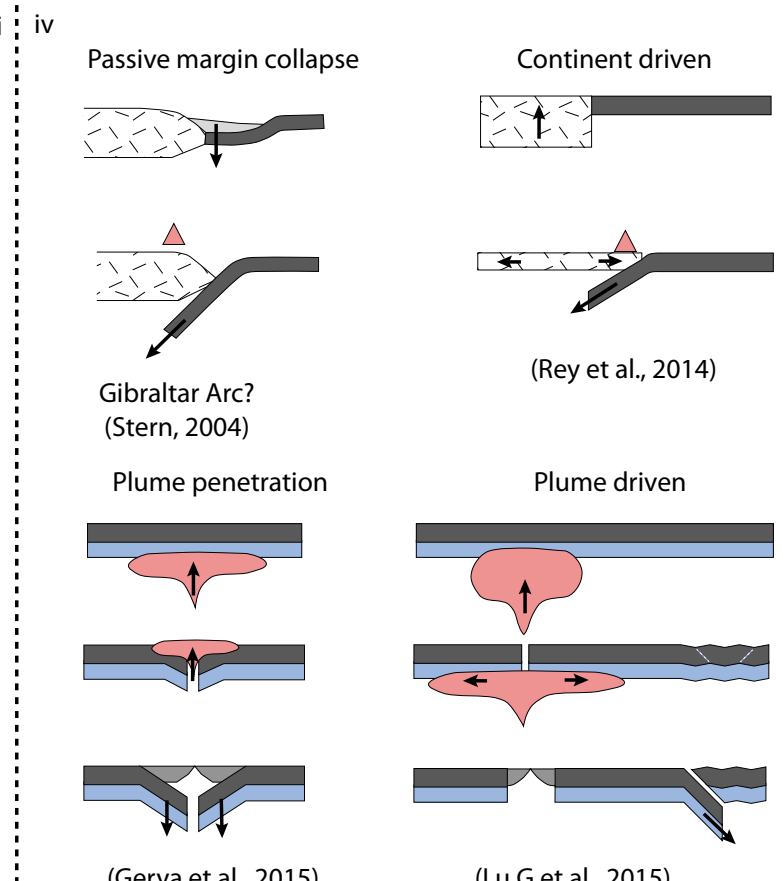

(Gerya et al., 2015)

Figure 5. Classification of proposed SI models. The classification is based on whether an external driving force is required (internally-driven vs. externally-driven) and whether an initial weakness is imposed (inherited plate weakness vs. self-nucleated shear zone). Arrows illustrate driving forces. Bottom notes in each model indicate natural examples or references. Modified from (Cooper and Taylor, 1985; Stern 2004; Govers and Wortel, 2005; Rey et al., 2014; Leng and Gurnis, 2015; Lu G et al., 2015; Maffione et al., 2015; Duretz et al., 2016; Stern and Gerya, 2018; Wan B et al., 2019; Crameri et al., 2020 ). 
While this review focuses on subduction initiation from a stagnant lid, it is useful for completeness and clarification to include all models even if they require ongoing plate tectonics.

i) Externally driven forcing with inherited plate weakness

- Conversion of oceanic transform faults/fracture zones: (Uyeda and Ben-Avraham, 1972; Casey and Dewey, 1984; Toth and Gurnis, 1998; Doin and Henry, 2001; Hall et al., 2003; Gurnis et al., 2004; Baes et al., 2011; Maffione et al., 2017; Guilmette et al., 2018; Zhong and Li, 2020);

- Inverse at (extinct) spreading ridges (Gurnis et al., 2004; Duretz et al., 2016; Keenan et al., 2016) or detachment faults (van Hinsbergen et al., 2015; Maffione et al., 2015);

- Inverse at COB (Zhong and Li, 2019);

- Episodic subduction (Crameri et al., 2020).

ii) Externally driven forcing with self-nucleated shear zone

- Plate rupture within an oceanic plate under compression forcing (McKenzie, 1977; Cloetingh et al., 1989; Shemenda, 1992; Thielmann amd Kaus, 2012; Zhong and Li, 2019; Crameri et al., 2020);

- Plate reorganization with sedimentary loading (Erickson and Arkani-Hamed, 1993);

- Compression forcing with various localization mechanisms, including shear heating (Crameri and Kaus, 2010; Thielmann and Kaus, 2012) and grain-size reduction (Bercovici and Ricard, 2005, 2013, 2014; Rozel et al., 2011);

- Plate rupture induced by plate acceleration (Agard et al., 2007);

- Subduction zone transference/trench jump (Mitchell, 1984; Stern, 2004; Tetreault and Buiter, 2012; Vogt and Gerya, 2014; Wan B et al., 2019; Wu et al., 2020);

- Subduction polarity reversal (Mitchell, 1984; Cooper and Taylor, 1985; Pysklywec, 2001; Stern, 2004; Faccenda et al., 2008; von Hagke et al., 2016; Crameri et al., 2020);

- Conversion of passive margin to subduction zone with suction force imposed at bottom boundary (Baes and Sobolev, 2017);

- Large asteroid impacts (Hansen, 2007; Yin A, 2012; O'Neill et al., 2020).

\section{iii) Internally driven forcing with inherited plate weakness}

- Gravitational collapse at transform faults/fracture zones (Karig, 1982; Matsumoto and Tomoda, 1983; Govers and Wortel, 2005; Mart et al., 2005; Gerya et al., 2008; Nikolaeva et al., 2008; Dymkova and Gerya, 2013; Zhou X et al., 2018; Zhou X et al., 2020), at continent-ocean interfaces (Goren et al., 2008; Nikolaeva et al., 2010, 2011; Marques et al., 2014), at oceanic plateaus (Nair and Chacko, 2008), or at relic arcs (Niu et al., 2003; Leng and Gurnis, 2015);

- Sedimentary loading and reactivation of margin faults (Erickson, 1993);

- Pre-existing slab pull force with imposed weak faults (Zhong and Gurnis, 1992, 1996; Zhong SJ et al., 1998) or weak crust layers (Crameri et al., 2012);

- Tensile decoupling of continent-ocean interface induced by basal traction (Kemp and Stevenson, 1996);

- Conversion of fracture zone triggered by suction from sinking slab (Baes et al., 2018);

- Lateral propagation of subduction (Zhou X et al., 2020);

- Mantle convection models with prescribed weak zones as plate boundaries (Davies, 1989; Puster et al., 1995; Zhong and Gurnis, 1995; Zhong SJ et al., 2000).

iv) Internally driven forcing with self-nucleated shear zone

- Passive margin collapse: triggered by hydrous upwelling (van der Lee et al., 2008), or by sedimentary loading (Fyfe and Leonardos, 1977; Cloetingh et al., 1989; Regenauer-Lieb et al., 2001);

- Plume injection (Ueda et al., 2008; Burov and Cloetingh, 2010; Gerya et al., 2015; Davaille et al., 2017);

- Plume induced mantle traction (Lu et al., 2015);

- Suction from sinking slab (Baes et al., 2018);

- Continent push (Marques et al., 2013; Rey et al., 2014);

- Small-scale convection (Solomatov, 2004);

- Transient mantle flow with damage and inheritance (Bercovici and Ricard, 2014);

- Initiation of global network of rifts due to thermal expansiondriven fracturing (Tang et al., 2020);

- Mantle convection models with self-organized plate behavior (e.g., Tackley, 2000a, b, c; Zhong SJ et al., 2007; Rolf and Tackley, 2011; Coltice et al., 2012; Rolf et al., 2012, 2018; Crameri and Tackley, 2014, 2016; Lourenço et al., 2016; Ballmer et al., 2017; Nakagawa and Iwamori, 2017), some of which have shown self-consistent subduction polarity reversal (Crameri and Tackley, 2014) and plate reorganization (Mallard et al., 2016; Coltice et al., 2019).

Caution must be advised for those models that do not prescribe initial weak seed but apply a friction coefficient $(\mu<\sim 0.1)$ that is much smaller than observed in laboratory measurements. Such a low yield stress is comparable to those with imposed initial weak zones. In this sense, we have classified models that require low plate strength into groups with inherited weakness. Models with continent-ocean transition (COT) are more ambiguous with regard to whether they assume inherited weakness. On one hand, the contact between continental and oceanic material is potentially a "weak point". On the other hand, however, such "weak points" seem to be relatively strong, as indicated by the lack of SI at passive margins even when the plate is under continent-continent collision (e.g. the Indian plate) (Crameri et al., 2020). Therefore, we consider the lithosphere with COT as a single plate unless the frictional coefficient of any of the two contacting plates is significantly lower $(\mu<\sim 0.1)$ than empirically observed values. Global mantle convection models naturally have self-consistent driving forces, if no prescribed surface boundary condition is applied. A pseudo-plastic rheology is commonly used to limit the stress and produce plate-like convection regimes in these models (e.g., Tackley, 2000b). Although the values of yield stress required for plate-like behavior are significantly smaller than the experimental estimates (Evans and Goetze, 1979; Tackley, 2000c; Hirth and Kohlstedt, 2004; Stein et al., 2004), it has been argued that the dimensional value of the pseudo-plastic yield stress in a geodynamic model is not directly comparable to that of an experiment because a realistic model for the Earth's mantle in terms of parameters is still out of reach in computational models (Coltice et al., 2017). It would be too crude to define, arbitrarily, a critical yield stress of the pseudo-plastic rheology and thus classify some of these models in the group that assume inherited plate weakness. Therefore, we have for simplicity assigned most global mantle convection models with self-organized plate behavior into Group 
(iv), although attention should be drawn to the factor that the yield stress in these models may still be too low, as indicated by the lack of asymmetric and one-sided subduction zones in these mantle convection models.

Although models in Group (iv) have internally driven forcing and self-nucleated weak zone, not all of them are capable of explaining initiation of the first subduction. For example, there was no pre-existing slab suction force before the first subduction began. Models with continent-ocean transition need some further consideration. On one hand, passive margin by definition is one of the elements of plate tectonics theory. It therefore cannot explain the first subduction initiation because, for passive margins to form, plate tectonics is implicitly assumed already to be operating. On the other hand, however, oceanic plateaus with sharp lateral density contrast, which has similar effect as continent-ocean transition, might exist prior to modern plate tectonics (Nair and Chacko, 2008). While the gravitational potential energy (GPE) stored within the density contrast may potentially induce large tectonic forces, which could be as large as $\sim 8 \times 10^{12} \mathrm{~N} / \mathrm{m}$ (Molnar et al., 1993; Ghosh et al., 2006), additional forces in the opposite direction are required to balance the GPE so as to avoid the vanishing of plateau (Faccenna et al., 2013). The question then becomes where this additional force is from and why the adjacent blocks were formed and maintained in an imbalanced state. In general, for a model to be considered successful in explaining the first $\mathrm{SI}$, it is crucial that the model starts from a single plate and required driving forces arise from processes that are independent of the operation of plate tectonics. Figure 6 illustrates several SI models that appear able to explain the first $\mathrm{SI}$ and thus the start of plate tectonics. In the model of Gerya et al. (2015) with melt-weakening rheology, a plume penetrates the overlying stagnant lithosphere, which is broken into several pieces that sink into the mantle, potentially providing suction forces to initiate subduction zones elsewhere and thus starting plate tectonics. In the model of Lu G et al. (2015), which includes a thermal-induced shear weakening mechanism, the plume does not penetrate the stagnant lithosphere but instead deflects and drives the overlying plate, which initiates a new subduction zone far away. In the model of Mallard et al. (2016), plates are produced self-consistently during mantle convection if the yield stress applied is between $100 \mathrm{MPa}$ and $350 \mathrm{MPa}$, which is comparable to the yield stress of oceanic lithosphere with hydrostatic pore pressure. The velocity patterns in models of Mallard et al. (2016) and Lu G et al. (2015) exhibit asymmetry comparable to that observed on present-day Earth (Figure 1), where the horizontal velocity of a subducting plate is significantly larger than that of an overriding plate.

\section{Discussion}

\subsection{Mantle Drag as the Missing Driving Force}

The driving mechanism of plate tectonics has been debated since the theory's birth more than 50 years ago. Previously, continental drift was thought to be driven by basal drag from mantle convection (Holmes, 1931; Hales, 1936). Since the advent of plate tectonics, however, the relationship has been reversed; it has become widely accepted that tectonic plates drive mantle convection (Forsyth and Uyeda, 1975; Chapple and Tullis, 1977; Hager and O'Con- nell, 1981; Anderson, 2002; Stern, 2004; Billen, 2008; van Hunen and Moyen, 2012; Turcotte and Schubert, 2014; Stern and Gerya, 2018). The negative buoyancy of subducted slabs leads to a gravitational pulling force that can be transmitted to the surface plate. This force, known as "slab pull" or "trench pull", is now widely credited in textbooks and research publications as the dominating driving force (Billen, 2008; van Hunen and Moyen, 2012; Turcotte and Schubert, 2014; Niu, 2020). In contrast, basal drag force from the convective mantle has generally been thought to be negligible or resistive (Stern, 2007; Billen, 2008; van Hunen and Moyen, 2012; Niu, 2020). The presence of a low viscosity asthenospheric layer is thought to be evidence that the shear traction from underlying mantle is likely to be weak.

However, present-day observations of plate motion and the deformation patterns of several major continental blocks are difficult to explain by slab pull alone. One of the best examples is probably the contrasting deformation between the eastern and western parts of the Indo-Australian Plate (Figure 7). The central Indian Ocean Basin in the western part is known for its intraplate seismicity and long wavelength buckling of the sea floor (Molnar et al., 1993; Gerbault, 2000). In contrast, the eastern part that is connected to subducting slabs under the Java-Sumatra trench is free of buckling (Gerbault, 2000). While slab pull force would generate only tensile stress within the plate, the buckling of the lithosphere indicates that there must be compressional forces from both the front and the end of the plate (Figure 7b). The India-Asia collision zone is a site that may provide such an extra force on the front side, which not only cancels the slab pull force from the deeper part of the trench but also exerts an extra compression on the horizontal domain of the subducting plate (Figure $7 \mathrm{~b}$ ). The compressional force to activate buckling of the Indian Basin is estimated to be $F=2.56 \times 10^{13} \mathrm{~N} / \mathrm{m}$ (Gerbault, 2000), in agreement with the force required to prevent the collapse of high plateaus such as the Tibetan plateau. However, the source of additional force in the back is more problematic. Ridge push is unlikely to be the missing force because it is one order of magnitude smaller than slab pull (Conrad and Lithgow-Bertelloni, 2004; van Hunen and Moyen, 2012; Turcotte and Schubert, 2014). Furthermore, if ridge push were dominating, buckling of oceanic lithosphere should have been a common observation at Atlantic-type passive margins, in particular those surrounding the African plate.

A breakthrough in the understanding of driving forces is the recognization of "slab suction" (Conrad and Lithgow-Bertelloni, 2002, 2004). "Slab suction" differs from "slab pull" in that it is induced by detached slabs without direct transmission of tensile stress to surface plates (Figure $2 b$ ). When a detached slab is sinking, it induces mantle flow that exerts shear traction on the base of the surface plates (Conrad and Lithgow-Bertelloni, 2004). We emphasize that it is the mantle flow and consequent basal drag that bridges the gravitational energy of the detached slab to the surface plates. In other words, basal drag, when powered by detached slabs, is simply an expression of slab suction. In this sense, mantle convection could provide an "induced" driving force to the surface plate, which may explain the missing pushing force that accounts for the buckling of oceanic lithosphere. It has been proposed that the present-day Tibet plateau is a "slab suction" 
(a) Plume penetration

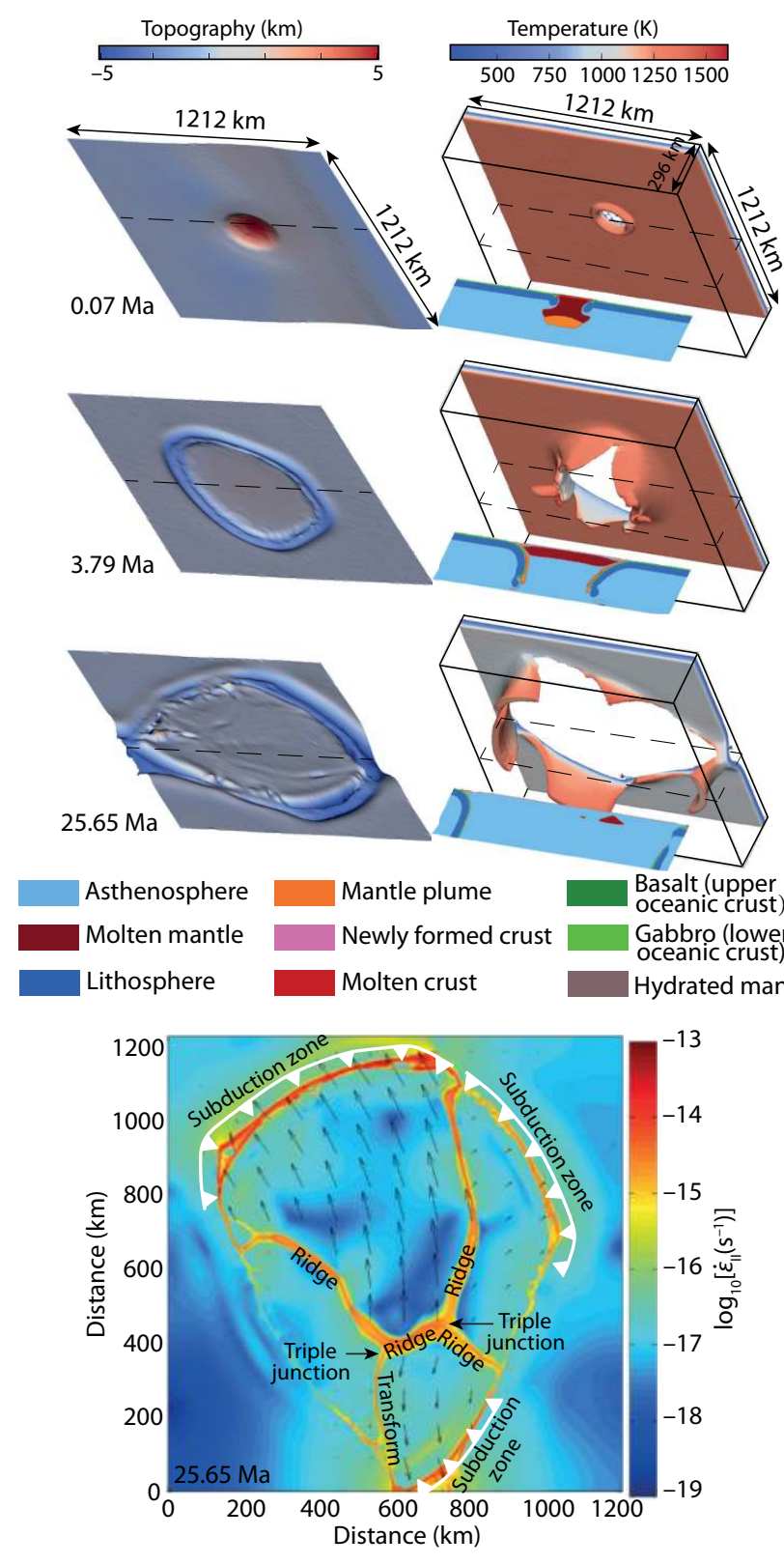

(b) Plume driven

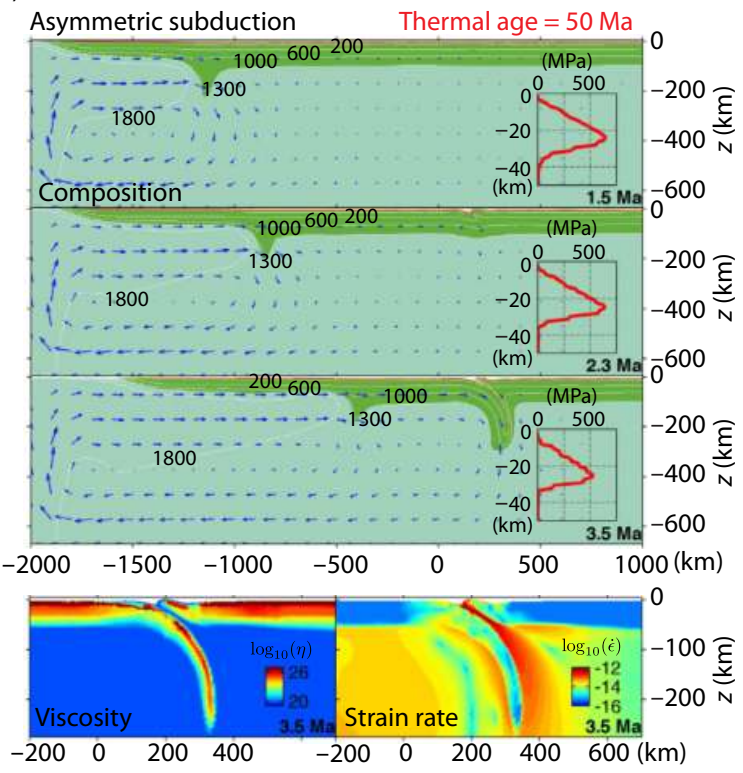

(c) Global mantle convection
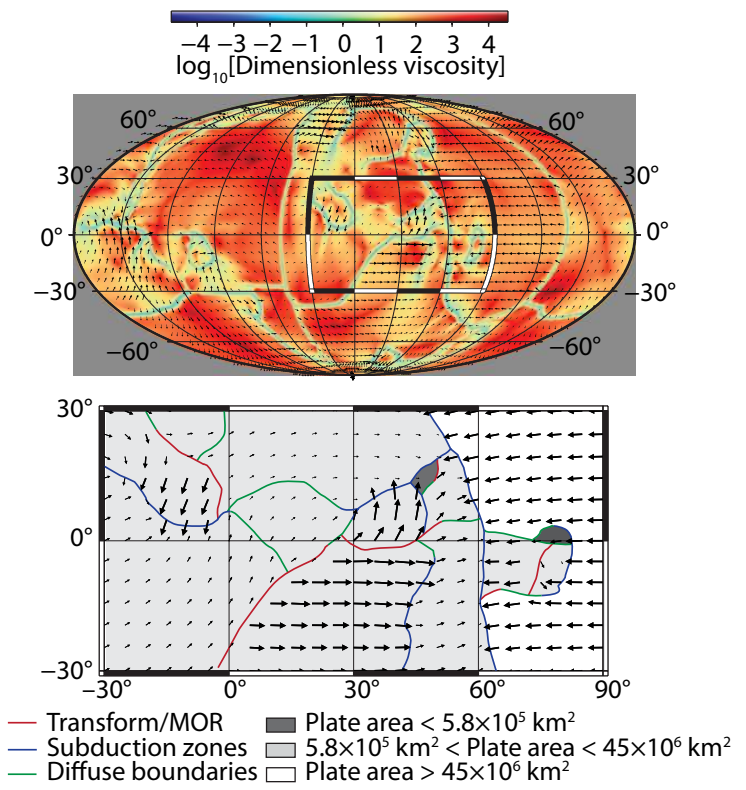

Figure 6. Candidate SI models that are capable of explaining the start of plate tectonics. (a) Subduction initiated due to plume penetration. Arrows show horizontal velocities of young, non-subducting plates moving towards retreating subducting slabs. Source: (Gerya et al., 2015). (b) Subduction initiation due to plume push. Arrows show velocities of mantle flow. Source: (Lu G et al., 2015). (c) Plate tectonics in mantle convection model. The yield stress values that produce plate-like behavior are between $100 \mathrm{MPa}$ and $350 \mathrm{MPa}$. Red line: mid-ocean ridges (MOR) or transform faults; blue line: subduction zones; green line: diffuse boundaries. Source: (Mallard et al., 2016).

type of mountain belt (Faccenna et al., 2013), which emphasizes that the force required to prevent the collapse of the high plateau originates in slab suction from lower mantle.

The ability of mantle flow to drive surface lithosphere has been demonstrated in recent numerical models (Lu G et al., 2015). They have estimated that the total drag force may exceed $10^{13} \mathrm{~N} / \mathrm{m}$, which is on the same order as slab pull force and thus confirms its ability to rupture a plate. Subsequent studies have further demonstrated that mantle drag force may eventually lead to supercontinent breakup or post-collisional orogeny (Dal Zilio et al., 2018,
2020; Zhang N et al., 2018; Chen L et al., 2020). One argument against such a driving mechanism is that basal drag is proportional to mantle viscosity and thus unlikely to be very large, due to the presence of the low-viscosity asthenospheric layer (Mueller and Phillips, 1991). However, Lu G et al. (2015) illustrate that the basal drag force is in fact insensitive to the viscosity in the asthenosphere during plume push (Figure 8). They show in their models that the total mantle drag force remains unchanged when asthenospheric viscosity decreases from $10^{20} \mathrm{~Pa} s$ to $10^{19} \mathrm{~Pa} \mathrm{~s}$, which instead results in a velocity that is 10 times larger (Figure 8) (Lu G et al., 2015). More recently, global mantle convection models 
(a)

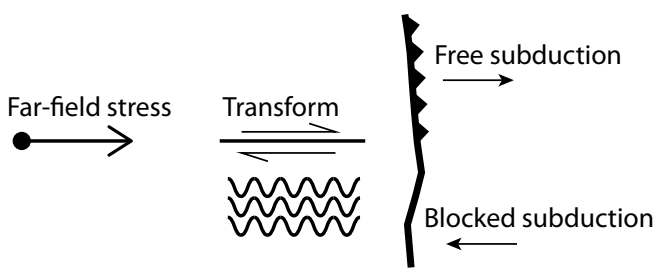

Net force within plate

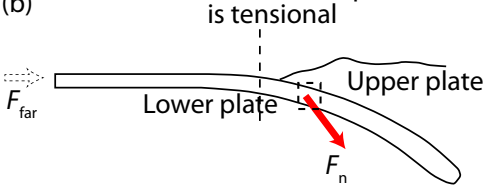

Free subduction
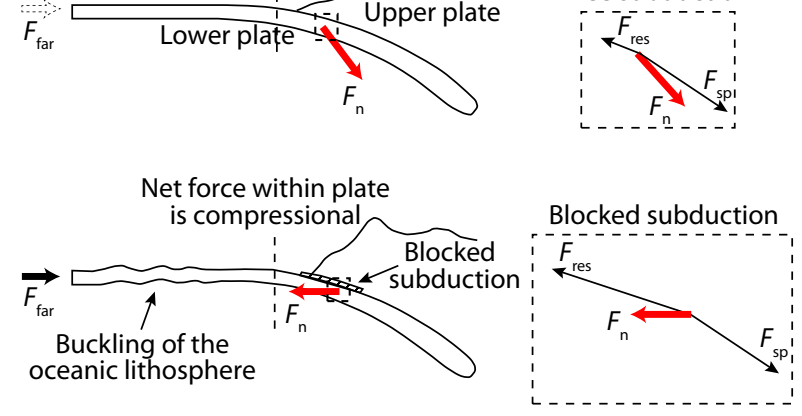

Figure 7. Comparison of free subduction and blocked subduction. (a) Schematic plot showing that buckling of oceanic lithosphere occurs under compressional stress when subduction is blocked and far-field stress remains. (b) Comparison of stress components in the cases with a free subducting slab (top) and blocked subduction (bottom). $F_{\text {far, }}$ far-field force; $F_{\text {sp, }}$ slab pull force; $F_{\text {res, }}$, resistance force; $F_{\mathrm{n}}$, net force acting on the slab at the trench or collision zone. Far-field stress is necessary to compress the surface plate from both the front and the back in order to activate buckling. Modified from (Agard et al., 2007).

(Coltice et al., 2019) have further illustrated quantitatively in a selfconsistent manner that, although slab pull may be the dominating first order force, $20 \%-50 \%$ of the surface is instead dragged by the interior.

\subsection{Switch of Driving Mechanism in Earth's History}

In the previous discussion we have highlighted that mantle drag is the acknowledged bridge between subducted slabs and surface plates. Here we further separate mantle drag from the slab suction mechanism and consider mantle drag as an end-member driving force. This clarification has several advantages in describing the driving mechanisms of plate tectonics. First, mantle drag is a force that is directly applied to the lithosphere, the same as other forces such as slab pull and ridge push, whereas slab suction requires convective mantle for bridging. Splitting mantle drag explicitly from slab suction mechanisms may lead to an improved understanding of tectonics by avoiding potential mixture of direct and indirect plate-driving forces. Second, mantle drag may better describe the mechanism of driving in broader situations, including continentward traction (Dal Zilio et al., 2018), in which the mantle flows away from the trench. Using "slab suction" in this case would be confusing, as "suction" implies movement towards the trench. The separation of the concepts of "mantle drag" from "slab suction" allows us to further generalize the role of mantle drag. We propose that it can arise from any density anomaly in the whole system. For example, in the slab suction mechanism, mantle drag is induced by high-density anomaly (detached slabs). Similarly, it can arise also from positive buoyancy (e.g. upwelling plume), which is then interpreted as "plume push". It should be noted that mantle drag driving is not limited to slab suction or plume push. Any cold or hot thermal anomalies in the mantle may provide similar mantle drag forces. Predictions of mantle flow from global tomographic models commonly show that large-scale mantle convection is a present-day driver of some plates (Becker and Faccenna, 2011; Ghosh and Holt, 2012). Particularly, mantle drag associated with large-scale convective mantle has been suggested as the main cause for the ongoing indentation of the Indian and Arabian plates into Eurasia (Becker and Faccenna, 2011;
Faccenna et al., 2013).

The above generalization leads us to propose a composite driving mechanism that may have operated during different stages of Earth history (Figure 9). As a reference, the convection-driven (Figure 9a) and slab-driven (Figure 9b) mechanisms are also illustrated. In the convection-driven mechanism (Figure 9a), first proposed almost a century ago (Holmes, 1931), plates are moving passively due to flow of sub-plate mantle. In contrast, in the slabdriven mechanism (Figure 9b), it is the subducted slabs (slab pull + slab suction) that power mantle flow. Stern (2007) argues that the convection-driven mechanism is an obsolete concept and that the slab-driven mechanism best explains present-day plate motions, while acknowledging that the relative importance between slab pull and slab suction remains a subject of debate (Conrad and Lithgow-Bertelloni, 2002, 2004; Stadler et al., 2010; Becker and Faccenna, 2011; Faccenna et al., 2012; Ghosh and Holt, 2012). The composite driving mechanism proposed here (Figure 9c) suggests that both convection-driven and slab-driven are important, although their relative contributions may vary from place to place and from time to time. In Mode A (slab-pull), a subducting slab pulls the surface plate and induces mantle flow. In Mode B (highdensity anomaly, slab suction), ongoing oceanic subduction does not exist, but there might be earlier-detached slabs that drive plate motions towards the trench. Modes A and B together are essentially identical to the modern view of a slab-driven mechanism (Figure 9b), incorporating the dominant driving forces for presentday Earth. Mode C (low-density anomaly, plume push) is identical to Mode B except that the high-density anomaly is replaced by a low-density anomaly such that all flow directions are opposite to Mode B. Mode D (plume-driven) is an extreme case of Mode C in which no initial weakness exists in the stagnant lid. If the upwelling is large enough, it may provide sufficient driving force to trigger a new subduction. Once subduction is initiated, the driving mechanism then switches to Modes $A$ and $B$, which again is driven primarily by slabs. During various stages of Earth's history, one or more of the above four modes may have operated together. However, not all of the mechanisms are equally important through time. It is likely that Modes A and B together have domin- 

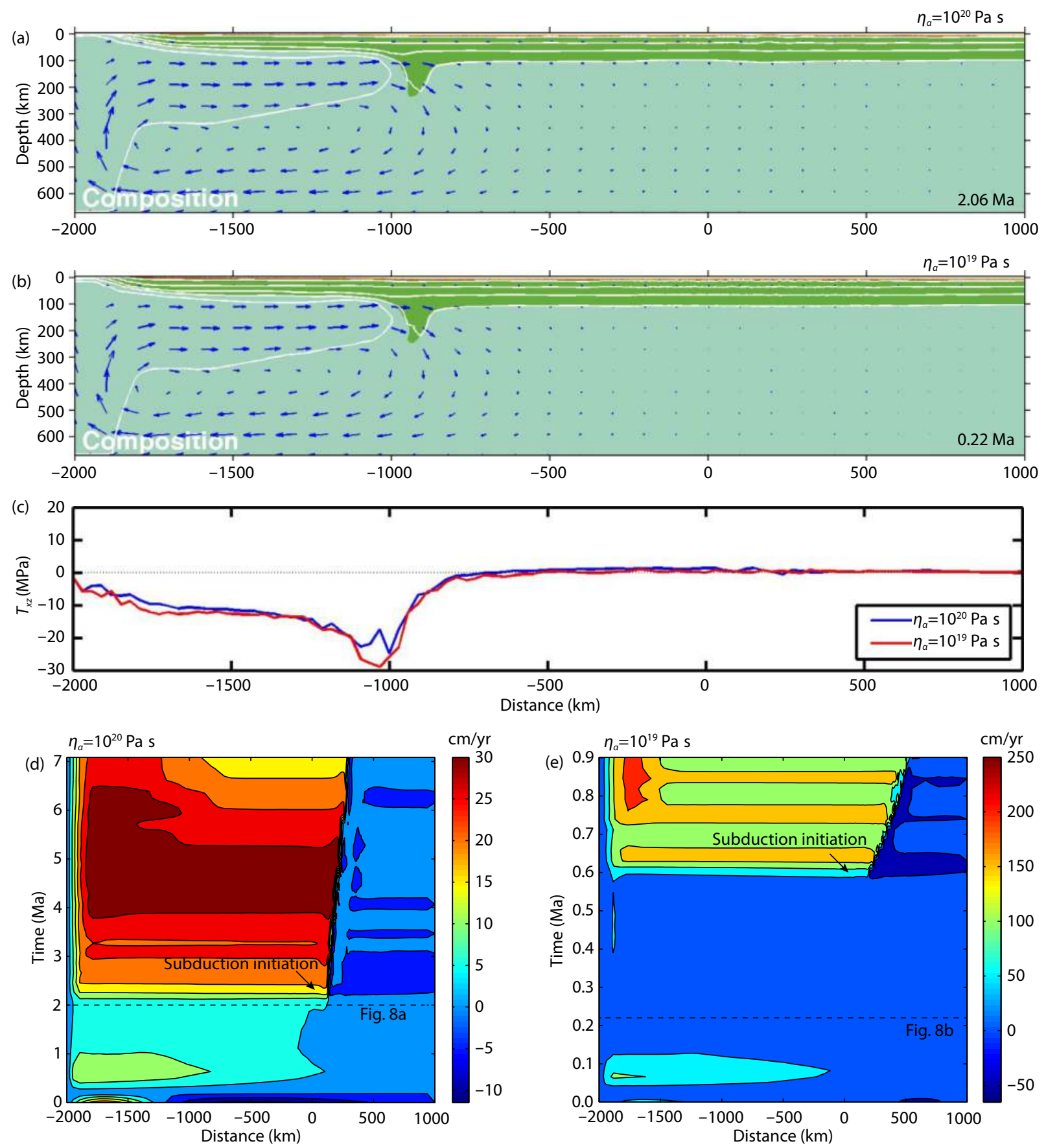

Figure 8. Comparison of basal drag force with different asthenospheric viscosities. (a, b) Plots of composition fields for models with lower-cutoff of asthenospheric viscosity: $10^{20} \mathrm{~Pa}$ s and $10^{19} \mathrm{~Pa}$ s, respectively. Arrows indicate flow field. Note that the flow patterns are nearly identical while the times are different. (c) Shear stress (basal drag) at depth of $50 \mathrm{~km}$ for these two models. The shear stresses are largely identical, although the asthenospheric viscosity in (b) is one order of magnitude lower than in (a). (d, e) Evolution of surface velocity for models with asthenospheric viscosity of $10^{20} \mathrm{~Pa}$ s and $10^{19} \mathrm{~Pa}$ s, respectively. Note that the velocity is one order of magnitude larger in the model with lower viscosity. Modified from Lu G et al. (2015).

ated whenever there have been subducting slabs. Plume-driven mechanisms (Mode C) may become important only when subducting slabs are absent, for example before the start of plate tectonics. Modes B and C, both of which involve mantle drag force, may be understood as convection-driven mechanisms. While we illustrate here only end-member modes of B and C, convectiondriving is not limited to slab suction and plume push, but in- cludes also large-scale mantle convection as indicated by largescale dynamic topography lows and highs (Yang and Gurnis, 2016). Given that mantle drag force is not negligible — in some cases it could be as large as slab pull (Conrad and Lithgow-Bertelloni, 2002, 2004), we argue that mantle drag is a first-order driving force and that convection-driving might be equally important as slab pull. We suggest that perturbations of interior mantle con- 
Early view (1930s-): Mantle convection driving

(a)

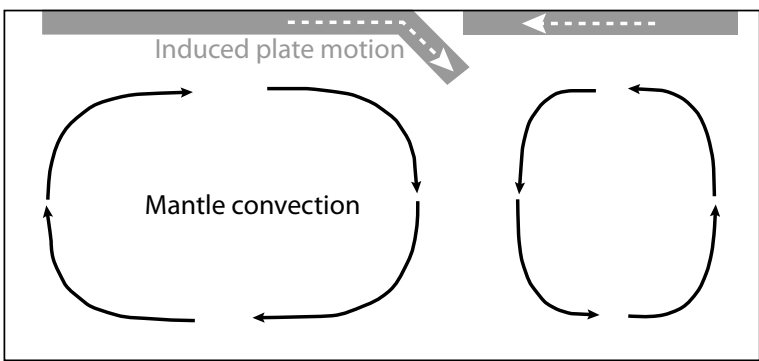

This study: Composite driving (slab pull + mantle drag)
Modern view (1970s-): Slab driving (slab pull + slab suction)

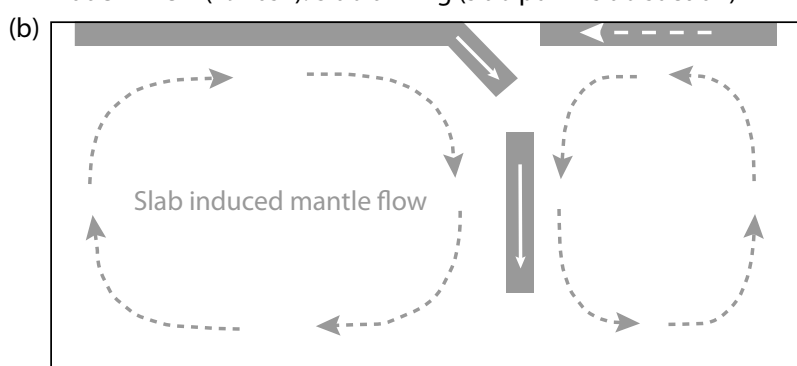

(c)
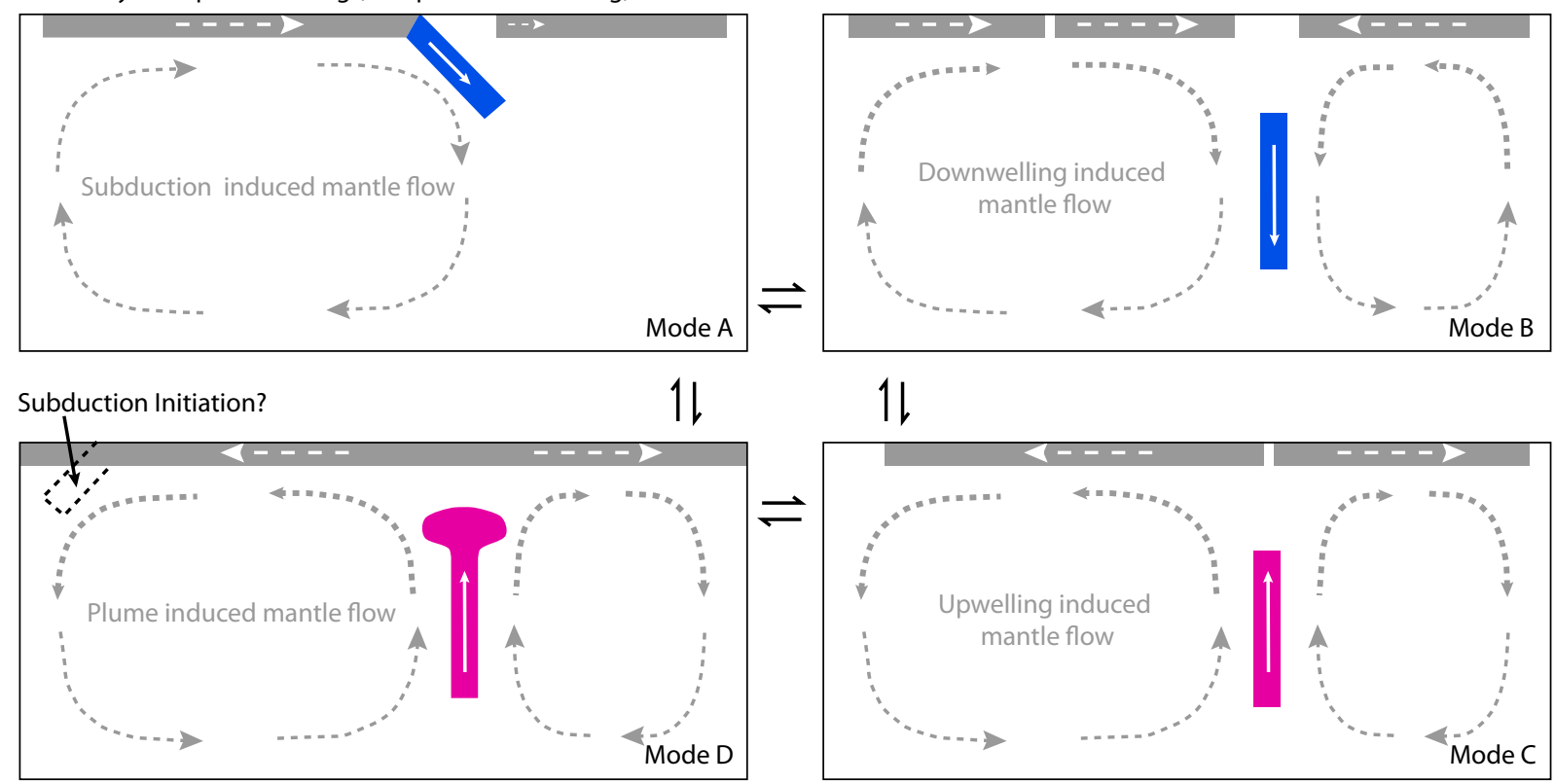

Figure 9. Various driving mechanisms of plate tectonics. (a) Early view: sub-plate mantle convection drives plate movements. (b) Modern view: tectonic plates (slab pull and slab suction) drive mantle convection. Note the movement of upper plate towards the trench driven by slab suction. (c) Composite driving (this study) with varying dominating driving forces at different stages. Mode A: slab pull drives surface plates and induces mantle convection. Mode B: High-density anomaly induces mantle flow that further drives surface plates (e.g. slab suction). Mode C: Low-density anomaly induces mantle flow that further drives surface plates (e.g. plume push). Note that Mode $C$ is identical to Mode B except that the directions of driving forces and corresponding mantle flow are all opposite. Mode $D$, an extreme case of Mode $C$, in which a new subduction is initiated from stagnant lid, such that the dominant driving mechanism switches to Mode A. See texts for discussion. Solid arrows indicate driving forces, while dashed lines indicate induced movements. However, thicker dashed lines of mantle flow show secondary driving force to surface plates.

vection may have produced a transient pulse of mantle drag force that might have kickstarted the first subduction (Mode D), thus resolving the paradox of the first SI.

It is worth noting that both plume push and slab suction as driving forces are induced by faster mantle flows, which can be understood as a convection-driven mechanism. However, a convectiondriven mechanism is not to be confused with a "bottom-up" tectonics (Chen L et al., 2020), which assumes that upwelling-dominated mantle convection, a system that does not include slab suction. The key point is that slab suction can be understood as either a "slab-driven" mechanism or a "convection-driven" mechanism. Therefore, it is clear that slab-driven and convection-driven mechanisms are overlapping concepts. While present-day Earth is a slab-driven system, convection-driven mechanism is not necessarily negligible. Instead, the fact that slab suction force could in some situations be as important as slab pull (Conrad and LithgowBertelloni, 2004) implies that mantle drag may be sufficiently large. Including slab suction into a generalized convection-driven mechanism allows to account naturally and consistently for re-initiation of subduction when a slab breaks off (Crameri and Tackley, 2015), as well as for self-organization of plates in global mantle convection models (Mallard et al., 2016; Coltice et al., 2017). On the other hand, emphasizing the importance of convection-driven mechanism does not necessarily contradict the dominance of slab-driven forces on present-day Earth. Convection-driven mechanisms may be important only locally for some plates. Whether the primary role of convective mantle is driving or resisting is most relevant to particular plates, i.e. whether underlying mantle flows faster or slower (e.g. Coltice et al., 2019). For the overall present-day lithosphere-mantle system, the view most consistent with present-day observations is that mantle convection is 
most likely driven predominantly by subducted slabs.

\subsection{Why Plate Tectonics is Rare on Terrestrial Planets}

In the previous section, we have proposed that mantle drag may have provided sufficient driving force to initiate subduction on Earth. However, as mantle drag exists on all planets, our proposal raises a new question: why do other planets not have plate tectonics? The answer to this question remains highly open. One of the key differences between Earth and other terrestrial planets is the presence of water on Earth.

First, the presence of pore-space water within Earth's rocks may significantly reduce the shear strength of our lithosphere. For a given basal drag force, a lithosphere with relatively low strength is more likely to experience plate rupture and subsequent initiation of subduction. Numerical models have suggested that subduction initiation is favored in lithosphere that is hydrated, compared to dry (Cloetingh et al., 1989; Regenauer-Lieb et al., 2001). However, as dehydration occurs during partial melting, the original stagnant lithosphere, as a residue of partial melting, before the onset of plate tectonics is assumed to have been dry. For the overall strength the lithosphere to have become reduced, there must have been a process to rehydrate the deep part of the lithosphere down to $50 \mathrm{~km}$. Mechanisms to explain how water goes into the interior include detachment faults at spreading systems (Guillot et al., 2015), slab bending at subduction zones (Ranero et al., 2003), and thermal cracking (Korenaga, 2007). However, care must be taken that any rehydration process that requires the operation of plate tectonics cannot be used as an explanation for the onset of plate tectonics. In this regard, thermal cracking is the most promising candidate that helps to explain strength reduction of plates before plate tectonics started (Korenaga, 2007). More recently, Tang CA et al. (2020) proposed a novel thermal-expansion-driven cracking model in which deep cracks are self-organized that may provide pathways for the rehydration of the lithosphere.

Second, and probably more important, the presence of water may help to maintain the operation of plate tectonics. It is believed that Venus's dynamic evolution is characterized by the episodic style of plate tectonics, in which long-lasting stagnant-lid periods are interrupted by short periods of global overturns (Moresi and Solomatov, 1998; Reese et al., 1999; Armann and Tackley, 2012). The overturn implies that internal convection makes it possible for the stagnant-lid lithosphere to break up. Recent study further suggests that subduction initiation may have occurred on Venus (Davaille et al., 2017). However, such overturn/subduction, if it existed, may have been local and short lasting (Fowler and O'Brien, 1996; Davaille et al., 2017; Uppalapati et al., 2020). On Earth, water release during subduction may lubricate the interface between plates (Gerya et al., 2008; Zheng and Chen, 2016; Sobolev and Brown, 2019), which could decouple the subducting plate and the overriding plate and stabilize the subduction system. If there were instances of subduction on Venus, the lack of water lubrication might have led to later "trench lock", prohibiting long-term global overturns. Furthermore, the presence of liquid water implies that a planet's surface temperature is not too high, a condition that increases the tendency of thermal localization (Crameri and Kaus, 2010; Karato and Barbot, 2018) or reduces healing rates of damage zones in the lithosphere (Landuyt and Bercovici, 2009).

\section{Summary and Outlook}

Initiation of the first subduction, and subsequently the start of plate tectonics, remains one of the biggest questions in Earth science. The main challenge is to identify a mechanism by which a strong lithosphere might break in the absence of plate tectonicsrelated weak zones and slab driving forces. In this review we have examined recent SI models that have greatly improved our understanding of conditions and possible processes of subduction initiation. In particular, we have examined the pre-requisites and the related driving mechanisms of each SI model to evaluate whether that model can account convincingly for the initiation of the first subduction. Plume-lithosphere interaction in regional models and mantle convection in global models are those that do not rely on the operation of existing plate tectonics. Re-examination of plate-driving mechanisms suggests that mantle drag may play an important role in driving surface plates - in particular, when slab pull force is missing - that could provide necessary driving forces to trigger the initiation of the first subduction. Full understanding of the first SI and the start of plate tectonics require 3-D global mantle convection models and/or laboratory analogue models that incorporate laboratory-based rock properties. Despite the great success of global mantle convection models in predicting plate behaviors, there is still a gap between the low friction coefficient required in numerical models and the high friction coefficients experimentally constrained for mantle materials. Future directions in subduction initiation modeling will need to focus on closing this gap.

\section{Acknowledgments}

We acknowledge the three anonymous reviewers for constructive comments and David Eisenman for English language editing, which greatly improved the manuscript. The research is sponsored by the National Key R \& D Program of China (grant No. 2017YFC0601206) and National Natural Science Foundation of China (grant No. 41774112).

\section{Box 1}

\section{Key terminologies}

Plate tectonics: Kinematic description of the surface lithosphere as plates, bounded by divergent, convergent, or transform plate boundaries, that move relative to each other.

Subduction: The process in which one lithospheric plate descends beneath another into the asthenosphere at convergent plate boundaries, leading to recycling of surface material into the mantle.

Subduction initiation: The onset of downward motion of a surface lithospheric plate, which later evolves into a self-sustaining subduction zone.

Mantle drag: Shear traction to the base of the lithosphere. It can be either driving of or resistant to plate movements, depending on the relative motion between plates and underlying mantle.

Slab pull: Tensional stress arising from negative buoyancy of a subducting slab that is directly connected to the surface lithosphere.

Ridge push: The gravitational body force on the elevated litho- 
sphere at mid-ocean ridges.

Slab suction: The mantle drag force exerted from mantle flow that is induced by detached slabs.

Plume push: The mantle drag force exerted from mantle flow that is induced by uprising plume heads.

"Top down" tectonics: A plate driving mechanism in which mantle flow is driven by negative buoyancy of oceanic slabs, including both slab pull and slab suction.

"Bottom up" tectonics: A plate driving mechanism in which plumes originating from core-mantle boundary drive plate motion.

Subduction-driven tectonics: Plates are seen as driven primarily by oceanic slabs, including by both slab pull and slab suction; often referred to as a synonym for "top down" tectonics.

Convection-driven tectonics: Mantle drag is seen as the primary driving force, including by both plume push and slab suction. (Not to be confused with "bottom up" tectonics, which does not include slab suction).

\section{References}

Agard, P., Jolivet, L., Vrielynck, B., Burov, E., and Monié, P. (2007). Plate acceleration: The obduction trigger?. Earth Planet. Sci. Lett., 258(3-4), 428-441. https://doi.org/10.1016/j.epsl.2007.04.002

Anderson, D. L. (2001). Geophysics. Top-down tectonics?. Science, 293(5537), 2016-2018. https://doi.org/10.1126/science.1065448

Anderson, D. L. (2002). Plate tectonics as a far-from-equilibrium self-organized system. In S. Stein, et al. (Eds.), Plate Boundary Zones (pp. 411-425). Washington: American Geophysical Union. https://doi.org/10.1029/GD030p0411

Armann, M., and Tackley, P. J. (2012). Simulating the thermochemical magmatic and tectonic evolution of Venus's mantle and lithosphere: Two-dimensional models. J. Geophys. Res.: Planets, 117(E12), E12003. https://doi.org/10.1029/2012JE004231

Baes, M., Govers, R., and Wortel, R. (2011). Subduction initiation along the inherited weakness zone at the edge of a slab: Insights from numerical models. Geophys. J. Int., 184(3), 991-1008. https://doi.org/10.1111/j.1365246X.2010.04896.x

Baes, M., and Sobolev, S. V. (2017). Mantle flow as a trigger for subduction initiation: a missing element of the wilson cycle concept. Geochem., Geophys., Geosyst., 18(12), 4469-4486. https://doi.org/10.1002/2017GC006962

Baes, M., Sobolev, S. V., and Quinteros, J. (2018). Subduction initiation in midocean induced by mantle suction flow. Geophys. J. Int., 215(3), 1515-1522. https://doi.org/10.1093/gji/ggy335

Ballmer, M. D., Houser, C., Hernlund, J. W., Wentzcovitch, R. M., and Hirose, K. (2017). Persistence of strong silica-enriched domains in the Earth's lower mantle. Nat. Geosci., 10(3), 236-240. https://doi.org/10.1038/ngeo2898

Becker, T. W., and Faccenna, C. (2011). Mantle conveyor beneath the Tethyan collisional belt. Earth Planet. Sci. Lett., 310(3-4), 453-461. https://doi.org/10.1016/j.epsl.2011.08.021

Bercovici, D. (2003). The generation of plate tectonics from mantle convection. Earth Planet. Sci. Lett., 205(3-4), 107-121. https://doi.org/10.1016/S0012821X(02)01009-9

Bercovici, D., and Ricard, Y. (2005). Tectonic plate generation and two-phase damage: Void growth versus grain size reduction. J. Geophys. Res.: Solid Earth, 110(B3), B03401. https://doi.org/10.1029/2004JB003181

Bercovici, D., and Ricard, Y. (2013). Generation of plate tectonics with twophase grain-damage and pinning: Source-sink model and toroidal flow. Earth Planet. Sci. Lett., 365, 275-288. https://doi.org/10.1016/j.epsl.2013.02.002

Bercovici, D., and Ricard, Y. (2014). Plate tectonics, damage and inheritance. Nature, 508(7497), 513-516. https://doi.org/10.1038/nature13072
Bercovici, D., Tackley, P. J., and Ricard, Y. (2015). The generation of plate tectonics from mantle dynamics. In G. Schubert (Ed.), Treatise on Geophysics (2nd ed, Vol. 7). Amsterdam: Elsevier. https://doi.org/10.1016/B978-0-44453802-4.00135-4

Billen, M. I. (2008). Modeling the dynamics of subducting slabs. Ann. Rev. Earth Planet. Sci., 36, 325-356. https://doi.org/10.1146/annurev.earth.36.031207.124129

Buffett, B. A. (2006). Plate force due to bending at subduction zones. J. Geophys. Res.: Solid Earth, 111(B9), B09405. https://doi.org/10.1029/2006JB004295

Buiter, S. J. H., Schreurs, G., Albertz, M., Gerya, T. V., Kaus, B., Landry, W., le Pourhiet, L., Mishin, Y., Egholm, D. L.,... Beaumont, C. (2016). Benchmarking numerical models of brittle thrust wedges. J. Struct. Geol., 92, 140-177. https://doi.org/10.1016/j.jsg.2016.03.003

Burov, E., and Cloetingh, S. (2010). Plume-like upper mantle instabilities drive subduction initiation. Geophys. Res. Lett., 37(3), L03309. https://doi.org/10.1029/2009gl041535

Burov, E. B. (2011). Rheology and strength of the lithosphere. Mar. Petrol. Geol., 28(8), 1402-1443. https://doi.org/10.1016/j.marpetgeo.2011.05.008

Byerlee, J. (1978). Friction of rocks. Pure Appl. Geophys., 116(4-5), 615-626. https://doi.org/10.1007/BF00876528

Casey, J. F., and Dewey, J. F. (1984). Initiation of subduction zones along transform and accreting plate boundaries, triple-junction evolution, and forearc spreading centres-implications for ophiolitic geology and obduction. Geological Society, London, Special Publication, 13, 269-290. https://doi.org/10.1144/GSL.SP.1984.013.01.22

Chapple, W. M., and Tullis, T. E. (1977). Evaluation of the forces that drive the plates. J. Geophys. Res., 82(14), 1967-1984. https://doi.org/10.1029/jb082i014p01967

Chen, L., Wang, X., Liang, X. F., Wan, B., and Liu, L. J. (2020). Subduction tectonics vs. Plume tectonics-Discussion on driving forces for plate motion. Sci. China Earth Sci., 63(3), 315-328. https://doi.org/10.1007/s11430019-9538-2

Cloetingh, S., Wortel, R., Vlaar, N. J. (1989). On the initiation of subduction. J. Geophys. Res., 129, 7-25.

Cloetingh, S. A. P. L., Wortel, M. J. R., and Vlaar, N. J. (1982). Evolution of passive continental margins and initiation of subduction zones. Nature, 297(5862), 139-142. https://doi.org/10.1038/297139a0

Coltice, N., Rolf, T., Tackley, P. J., and Labrosse, S. (2012). Dynamic causes of the relation between area and age of the Ocean Floor. Science, 336(6079), 335-338. https://doi.org/10.1126/science.1219120

Coltice, N., Gérault, M., and Ulvrová, M. (2017). A mantle convection perspective on global tectonics. Earth-Sci. Rev., 165, 120-150. https://doi.org/10.1016/j.earscirev.2016.11.006

Coltice, N., Husson, L., Faccenna, C., and Arnould, M. (2019). What drives tectonic plates?. Sci. Adv., 5(10), eaax4295. https://doi.org/10.1126/sciadv.aax4295

Conrad, C. P., and Lithgow-Bertelloni, C. (2002). How mantle slabs drive plate tectonics. Science, 298(5591), 207-209. https://doi.org/10.1126/science.1074161

Conrad, C. P., and Lithgow-Bertelloni, C. (2004). The temporal evolution of plate driving forces: Importance of "slab suction" versus "slab pull" during the Cenozoic. J. Geophys. Res.: Solid Earth, 109(B10), B10407. https://doi.org/10.1029/2004JB002991

Cooper, P. A., and Taylor, B. (1985). Polarity reversal in the Solomon Islands arc. Nature, 314(6010), 428-430. https://doi.org/10.1038/314428a0

Crameri, F., and Kaus, B. J. P. (2010). Parameters that control lithospheric-scale thermal localization on terrestrial planets. Geophys. Res. Lett., 37(9), L09308. https://doi.org/10.1029/2010GL042921

Crameri, F., Tackley, P. J., Meilick, I., Gerya, T. V., and Kaus, B. J. P. (2012). A free plate surface and weak oceanic crust produce single-sided subduction on Earth. Geophys. Res. Lett., 39(3), L03306. https://doi.org/10.1029/2011GL050046

Crameri, F., and Tackley, P. J. (2014). Spontaneous development of arcuate single-sided subduction in global 3-D mantle convection models with a free surface. J. Geophys. Res.: Solid Earth, 119(7), 5921-5942. 
https://doi.org/10.1002/2014JB010939

Crameri, F., and Tackley, P. J. (2015). Parameters controlling dynamically selfconsistent plate tectonics and single-sided subduction in global models of mantle convection. J. Geophys. Res.: Solid Earth, 120(5), 3680-3706. https://doi.org/10.1002/2014JB011664

Crameri, F., and Tackley, P. J. (2016). Subduction initiation from a stagnant lid and global overturn: new insights from numerical models with a free surface. Prog. Earth Planet. Sci., 3(1), 30. https://doi.org/10.1186/s40645-0160103-8

Crameri, F., Conrad, C. P., Montési, L., and Lithgow-Bertelloni, C. R. (2019). The dynamic life of an oceanic plate. Tectonophysics, 760, 107-135. https://doi.org/10.1016/j.tecto.2018.03.016

Crameri, F., Magni, V., Domeier, M., Shephard, G. E., Chotalia, K., Cooper, G., Eakin, C. M., Grima, A. G., Gürer, D.,... Thielmann, M. (2020). A transdisciplinary and community-driven database to unravel subduction zone initiation. Nat. Commun., 11(1), 3750. https://doi.org/10.1038/s41467020-17522-9

Dal Zilio, L., Faccenda, M., and Capitanio, F. (2018). The role of deep subduction in supercontinent breakup. Tectonophysics, 746, 312-324. https://doi.org/10.1016/j.tecto.2017.03.006

Dal Zilio, L., Kissling, E., Gerya, T., and van Dinther, Y. (2020). Slab rollback orogeny model: a test of concept. Geophys. Res. Lett., 47(18), e2020GL089917. https://doi.org/10.1029/2020GL089917

Davaille, A., Smrekar, S. E., and Tomlinson, S. (2017). Experimental and observational evidence for plume-induced subduction on Venus. Nat. Geosci., 10(5), 349-355. https://doi.org/10.1038/ngeo2928

Davies, G. F. (1989). Mantle convection model with a dynamic plate: topography, heat flow and gravity anomalies. Geophys. J. Int., 98(3), 461-464. https://doi.org/10.1111/j.1365-246X.1989.tb02283.x

Davies, G. F. (2009). Effect of plate bending on the Urey ratio and the thermal evolution of the mantle. Earth Planet. Sci. Lett., 287(3-4), 513-518. https://doi.org/10.1016/j.epsl.2009.08.038

Doin, M. P., and Henry, P. (2001). Subduction initiation and continental crust recycling: the roles of rheology and eclogitization. Tectonophysics, 342(1-2), 163-191. https://doi.org/10.1016/S0040-1951(01)00161-5

Duretz, T., Agard, P., Yamato, P., Ducassou, C., Burov, E. B., and Gerya, T. V. (2016). Thermo-mechanical modeling of the obduction process based on the Oman Ophiolite case. Gondw. Res., 32, 1-10.

https://doi.org/10.1016/j.gr.2015.02.002

Dymkova, D., and Gerya, T. (2013). Porous fluid flow enables oceanic subduction initiation on Earth. Geophys. Res. Lett., 40(21), 5671-5676. https://doi.org/10.1002/2013GL057798

Erickson, S. G. (1993). Sedimentary loading, lithospheric flexure, and subduction initiation at passive margins. Geology, 21(2), 125-128. https://doi.org/10.1130/0091-7613(1993)021<0125:SLLFAS>2.3.CO;2

Erickson, S. G., and Arkani-Hamed, J. (1993). Subduction initiation at passive margins: the Scotian Basin, Eastern Canada as a potential example. Tectonics, 12(3), 678-687. https://doi.org/10.1029/92TC02602

Evans, B., and Goetze, C. (1979). The temperature variation of hardness of olivine and its implication for polycrystalline yield stress. J. Geophys. Res.: Solid Earth, 84(B10), 5505-5524. https://doi.org/10.1029/JB084iB10p05505

Faccenda, M., Gerya, T. V., and Chakraborty, S. (2008). Styles of post-subduction collisional orogeny: Influence of convergence velocity, crustal rheology and radiogenic heat production. Lithos, 103(1-2), 257-287. https://doi.org/10.1016/j.lithos.2007.09.009

Faccenna, C., Becker, T. W., Lallemand, S., and Steinberger, B. (2012). On the role of slab pull in the Cenozoic motion of the Pacific plate. Geophys. Res. Lett., 39(3), L03305. https://doi.org/10.1029/2011GL050155

Faccenna, C., Becker, T. W., Conrad, C. P., and Husson, L. (2013). Mountain building and mantle dynamics. Tectonics, 32(1), 80-93. https://doi.org/10.1029/2012TC003176

Forsyth, D. W., and Uyeda, S. (1975). On the relative importance of the driving forces of plate motion. Geophys. J. R. Astr. Soc., 43(1), 163-200. https://doi.org/10.1111/j.1365-246X.1975.tb00631.x

Fowler, A. C., and O'Brien, S. B. G. (1996). A mechanism for episodic subduction on Venus. J. Geophys. Res.: Planets, 101(E2), 4755-4763.
https://doi.org/10.1029/95JE03261

Fyfe, W. S., and Leonardos, Jr. O. H. (1977). Speculations on the causes of crustal rifting and subduction, with applications to the atlantic margin of Brazil. Tectonophysics, 42(1), 29-36. https://doi.org/10.1016/0040-1951(77)90015-4

Gerbault, M. (2000). At what stress level is the central Indian Ocean lithosphere buckling?. Earth Planet. Sci. Lett., 178(1-2), 165-181. https://doi.org/10.1016/S0012-821X(00)00054-6

Gerya, T. (2011). Future directions in subduction modeling. J. Geodyn., 52(5), 344-378. https://doi.org/10.1016/j.jog.2011.06.005

Gerya, T. V., Connolly, J. A. D., and Yuen, D. A. (2008). Why is terrestrial subduction one-sided?. Geology, 36(1), 43-46. https://doi.org/10.1130/G24060A.1

Gerya, T. V., Stern, R. J., Baes, M., Sobolev, S. V., and Whattam, S. A. (2015). Plate tectonics on the Earth triggered by plume-induced subduction initiation. Nature, 527(7577), 221-225. https://doi.org/10.1038/nature15752

Ghosh, A., Holt, W. E., Flesch, L. M., and Haines, A. J. (2006). Gravitational potential energy of the Tibetan Plateau and the forces driving the Indian plate. Geology, 34(5), 321-324. https://doi.org/10.1130/G22071.1

Ghosh, A., and Holt, W. E. (2012). Plate motions and stresses from global dynamic models. Science, 335(6070), 839-843. https://doi.org/10.1126/science.1214209

Goetze, C., and Evans, B. (1979). Stress and temperature in bending lithosphere as constrained by experimental rock mechanics. Geophys. J. R. Astr. Soc., 59(3), 463-478. https://doi.org/10.1111/j.1365-246X.1979.tb02567.x

Goren, L., Aharonov, E., Mulugeta, G., Koyi, H. A., and Mart, Y. (2008). Ductile deformation of passive margins: A new mechanism for subduction initiation. J. Geophys. Res.: Solid Earth, 113(B8), B08411. https://doi.org/10.1029/2005JB004179

Govers, R., and Wortel, M. J. R. (2005). Lithosphere tearing at STEP faults: Response to edges of subduction zones. Earth and Planetary Science Letters, 236(1-2), 505-523. https://doi.org/10.1016/j.epsl.2005.03.022

Guillot, S., Schwartz, S., Reynard, B., Agard, P., and Prigent, C. (2015). Tectonic significance of serpentinites. Tectonophysics, 646, 1-19. https://doi.org/10.1016/j.tecto.2015.01.020

Guilmette, C., Smit, M. A., van Hinsbergen, D. J. J., Gürer, D., Corfu, F., Charette, B., Maffione, M., Rabeau, O., and Savard, D. (2018). Forced subduction initiation recorded in the sole and crust of the Semail Ophiolite of Oman. Nat. Geosci., 11(9), 688-695. https://doi.org/10.1038/s41561-018-0209-2

Gurnis, M., Hall, C., and Lavier, L. (2004). Evolving force balance during incipient subduction. Geochem., Geophys., Geosyst., 5(7), Q07001. https://doi.org/10.1029/2003GC000681

Hager, B. H., and O'Connell, R. J. (1981). A simple global model of plate dynamics and mantle convection. J. Geophys. Res.: Solid Earth, 86(B6), 4843-4867. https://doi.org/10.1029/JB086iB06p04843

Hales, A. L. (1936). Convection currents in the Earth. Geophysical Supplements to the Monthly Notices of the Royal Astronomical Society, 3(9), 372-379. https://doi.org/10.1111/j.1365-246X.1936.tb01744.x

Hall, C. E., Gurnis, M., Sdrolias, M., Lavier, L. L., and Müller, R. D. (2003). Catastrophic initiation of subduction following forced convergence across fracture zones. Earth Planet. Sci. Lett., 212(1-2), 15-30. https://doi.org/10.1016/S0012-821X(03)00242-5

Hansen, V. L. (2007). Subduction origin on early Earth: A hypothesis. Geology, 35(12), 1059-1062. https://doi.org/10.1130/G24202A.1

Hirth, G., and Kohlstedt, D. L. (2004). Rheology of the upper mantle and the mantle wedge: a view from the experimentalists. In J. Eiler (Ed.), Inside the Subduction Factory (Vol. 138, pp. 83-105). Washington: American Geophysical Union. https://doi.org/10.1029/138GM06

Holmes, A. (1931). Radioactivity and earth movements. Trans. Geol. Soc. Glasgow, 18(3), 559-606. https://doi.org/10.1144/transglas.18.3.559

Hunter, J., and Watts, A. B. (2016). Gravity anomalies, flexure and mantle rheology seaward of circum-Pacific trenches. Geophys. J. Int., 207(1), 288-316. https://doi.org/10.1093/gji/ggw275

Johnson, T. E., Brown, M., Kaus, B. J. P., and VanTongeren, J. A. (2014). Delamination and recycling of archaean crust caused by gravitational instabilities. Nat. Geosci., 7(1), 47-52. https://doi.org/10.1038/ngeo2019

Karato, S. I., and Barbot, S. (2018). Dynamics of fault motion and the origin of 
contrasting tectonic style between Earth and Venus. Sci. Rep., 8(1), 11884. https://doi.org/10.1038/s41598-018-30174-6

Karig, D. E. (1982). Initiation of subduction zones: implications for arc evolution and ophiolite development. Geol. Soc. Lond. Spec. Pub., 10(1), 563-576. https://doi.org/10.1144/GSL.SP.1982.010.01.37

Keenan, T. E., Encarnación, J., Buchwaldt, R., Fernandez, D., Mattinson, J., Rasoazanamparany, C., and Luetkemeyer, P. B. (2016). Rapid conversion of an oceanic spreading center to a subduction zone inferred from highprecision geochronology. Proc. Natl. Acad. Sci. USA, 113(47), E7359-E7366. https://doi.org/10.1073/pnas.1609999113

Kemp, D. V, and Stevenson, D. J. (1996). A tensile, flexural model for the initiation of subduction. Geophys. J. Int., 125(1), 73-93. https://doi.org/10.1111/j.1365-246X.1996.tb06535.x

Kreemer, C. (2009). Absolute plate motions constrained by shear wave splitting orientations with implications for hot spot motions and mantle flow. Journal of Geophysical Research: Solid Earth, 114(10), 1-18. https://doi.org/10.1029/2009JB006416

Korenaga, J. (2007). Thermal cracking and the deep hydration of oceanic lithosphere: A key to the generation of plate tectonics?. J. Geophys. Res.: Solid Earth, 112(B5), B05408. https://doi.org/10.1029/2006JB004502

Korenaga, J. (2013). Initiation and evolution of plate tectonics on earth: theories and observations. Annu. Rev. Earth Planet. Sci., 41, 117-151. https://doi.org/10.1146/annurev-earth-050212-124208

Kreemer, C., Blewitt, G., and Klein, E. C. (2014). A geodetic plate motion and Global Strain Rate Model. Geochem., Geophys., Geosyst., 15(10), 3849-3889. https://doi.org/10.1002/2014GC005407

Landuyt, W., and Bercovici, D. (2009). Formation and structure of lithospheric shear zones with damage. Phys. Earth Planet. Inter., 175(3-4), 115-126. https://doi.org/10.1016/j.pepi.2009.03.005

Leng, W., and Gurnis, M. (2015). Subduction initiation at relic arcs. Geophys. Res. Lett., 42(17), 7014-7021. https://doi.org/10.1002/2015GL064985

Li, Z. H., and Ribe, N. M. (2012). Dynamics of free subduction from 3-D boundary element modeling. J. Geophys. Res.: Solid Earth, 117(B6), B06408. https://doi.org/10.1029/2012JB009165

Lithgow-Bertelloni, C., and Silver, P. G. (1998). Dynamic topography, plate driving forces and the African superswell. Nature, 395(6699), 269-272. https://doi.org/10.1038/26212

Lourenço, D. L., Rozel, A., and Tackley, P. J. (2016). Melting-induced crustal production helps plate tectonics on Earth-like planets. Earth Planet. Sci. Lett., 439, 18-28. https://doi.org/10.1016/j.epsl.2016.01.024

Lourenço, D. L., Rozel, A. B., Ballmer, M. D., and Tackley, P. J. (2020). Plutonicsquishy lid: a new global tectonic regime generated by intrusive magmatism on earth-like planets. Geochem., Geophys., Geosyst., 21(4), e2019GC008756. https://doi.org/10.1029/2019GC008756

Lu, G., Kaus, B. J. P., Zhao, L., and Zheng, T. Y. (2015). Self-consistent subduction initiation induced by mantle flow. Terra Nova, 27(2), 130-138. https://doi.org/10.1111/ter.12140

Maffione, M., Thieulot, C., van Hinsbergen, D. J. J., Morris, A., Plümper, O., and Spakman, W. (2015). Dynamics of intraoceanic subduction initiation: 1. Oceanic detachment fault inversion and the formation of supra-subduction zone ophiolites. Geochem., Geophys., Geosyst., 16(6), 1753-1770. https://doi.org/10.1002/2015GC005746

Maffione, M., van Hinsbergen, D. J. J., de Gelder, G. I. N. O., van der Goes, F. C., and Morris, A. (2017). Kinematics of Late Cretaceous subduction initiation in the Neo-Tethys Ocean reconstructed from ophiolites of Turkey, Cyprus, and Syria. J. Geophys. Res.: Solid Earth, 122(5), 3953-3976. https://doi.org/10.1002/2016JB013821

Mallard, C., Coltice, N., Seton, M., Müller, R. D., and Tackley, P. J. (2016). Subduction controls the distribution and fragmentation of Earth's tectonic plates. Nature, 535(7610), 140-143. https://doi.org/10.1038/nature17992

Marques, F. O., Nikolaeva, K., Assumpção, M., Gerya, T. V., Bezerra, F. H. R., do Nascimento, A. F., and Ferreira, J. M. (2013). Testing the influence of far-field topographic forcing on subduction initiation at a passive margin. Tectonophysics, 608, 517-524. https://doi.org/10.1016/j.tecto.2013.08.035

Marques, F. O., Cabral, F. R., Gerya, T. V., Zhu, G., and May, D. A. (2014).
Subduction initiates at straight passive margins. Geology, 42(4), 331-334. https://doi.org/10.1130/G35246.1

Mart, Y., Aharonov, E., Mulugeta, G., Ryan, W., Tentler, T., and Goren, L. (2005). Analogue modelling of the initiation of subduction. Geophys. J. Int., 160(3), 1081-1091. https://doi.org/10.1111/j.1365-246X.2005.02544.x

Matsumoto, T., and Tomoda, Y. (1983). Numerical simulation of the initiation of subduction at the fracture zone. J. Phys. Earth, 31(3), 183-194. https://doi.org/10.4294/jpe1952.31.183

McKenzie, D. P. (1977). The initiation of trenches: a finite amplitude instability. In M. Talwani and W. C. Pitman III (Eds.), Island Arcs, Deep Sea Trenches and Back-Arc basins (Vol. 1, pp. 57-61). Washington: AGU.

https://doi.org/10.1029/ME001p0057

Mitchell, A. H. G. (1984). Initiation of subduction by post-collision foreland thrusting and back-thrusting. J. Geodyn., 1(2), 103-120. https://doi.org/10.1016/0264-3707(84)90023-1

Molnar, P., England, P., and Martinod, J. (1993). Mantle dynamics, uplift of the Tibetan Plateau, and the Indian Monsoon. Rev. Geophys., 31(4), 357-396. https://doi.org/10.1029/93RG02030

Moresi, L., and Solomatov, V. (1998). Mantle convection with a brittle lithosphere: thoughts on the global tectonic styles of the Earth and Venus. Geophys. J. Int., 133(3), 669-682. https://doi.org/10.1046/j.1365246X.1998.00521.x

Moresi, L. N., and Solomatov, V. S. (1995). Numerical investigation of 2D convection with extremely large viscosity variations. Phys. Fluids, 7(9), 2154-2162. https://doi.org/10.1063/1.868465

Mueller, S., and Phillips, R. J. (1991). On the initiation of subduction. J. Geophys. Res.: Solid Earth, 96(B1), 651-665. https://doi.org/10.1029/90JB02237

Nair, R., and Chacko, T. (2008). Role of oceanic plateaus in the initiation of subduction and origin of continental crust. Geology, 36(7), 583-586. https://doi.org/10.1130/G24773A.1

Nakagawa, T., and Iwamori, H. (2017). Long-term stability of plate-like behavior caused by hydrous mantle convection and water absorption in the deep mantle. J. Geophys. Res.: Solid Earth, 122(10), 8431-8445. https://doi.org/10.1002/2017JB014052

Nikolaeva, K., Gerya, T. V., and Connolly, J. A. D. (2008). Numerical modelling of crustal growth in intraoceanic volcanic arcs. Phys. Earth Planet. Inter., 171(14), 336-356. https://doi.org/10.1016/j.pepi.2008.06.026

Nikolaeva, K., Gerya, T. V., and Marques, F. O. (2010). Subduction initiation at passive margins: Numerical modeling. J. Geophys. Res.: Solid Earth, 115(B3), B03406. https://doi.org/10.1029/2009JB006549

Nikolaeva, K., Gerya, T. V., and Marques, F. O. (2011). Numerical analysis of subduction initiation risk along the Atlantic American passive margins. Geology, 39(5), 463-466. https://doi.org/10.1130/G31972.1

Niu, Y. L., O'Hara, M. J., and Pearce, J. A. (2003). Initiation of subduction zones as a consequence of lateral compositional buoyancy contrast within the lithosphere: a petrological perspective. J. Petrol., 44(5), 851-866. https://doi.org/10.1093/petrology/44.5.851

Niu, Y. L. (2020). On the cause of continental breakup: A simple analysis in terms of driving mechanisms of plate tectonics and mantle plumes. J. Asian Earth Sci., 194, 104367. https://doi.org/10.1016/j.jseaes.2020.104367

O'Neill, C., Marchi, S., Bottke, W., and Fu, R. (2020). The role of impacts on Archaean tectonics. Geology, 48(2), 174-178. https://doi.org/10.1130/G46533.1

Puster, P., Hager, B. H., and Jordan, T. H. (1995). Mantle convection experiments with evolving plates. Geophys. Res. Lett., 22(16), 2223-2226. https://doi.org/10.1029/95GL01998

Pysklywec, R. N. (2001). Evolution of subducting mantle lithosphere at a continental plate boundary. Geophys. Res. Lett., 28(23), 4399-4402. https://doi.org/10.1029/2001GL013567

Ranalli, G. (1995). Rheology of the Earth (2nd ed.). London: Chapman \& Hall.

Ranero, C. R., Morgan, J. P., McIntosh, K., and Reichert, C. (2003). Bendingrelated faulting and mantle serpentinization at the Middle America trench. Nature, 425(6956), 367-373. https://doi.org/10.1038/nature01961

Reese, C. C., Solomatov, V. S., and Moresi, L. N. (1999). Non-newtonian stagnant lid convection and magmatic resur facing on venus. Icarus, 139(1), 67-80. 
https://doi.org/10.1006/icar.1999.6088

Regenauer-Lieb, K., Yuen, D. A., and Branlund, J. (2001). The initiation of subduction: criticality by addition of water?. Science, 294(5542), 578-580. https://doi.org/10.1126/science.1063891

Rey, P. F., Coltice, N., and Flament, N. (2014). Spreading continents kick-started plate tectonics. Nature, 513(7518), 405-408. https://doi.org/10.1038/nature13728

Ribe, N. M. (2010). Bending mechanics and mode selection in free subduction: a thin-sheet analysis. Geophys. J. Int., 180(2), 559-576. https://doi.org/10.1111/j.1365-246X.2009.04460.x

Rolf, T., and Tackley, P. J. (2011). Focussing of stress by continents in 3D spherical mantle convection with self-consistent plate tectonics. Geophys. Res. Lett., 38(18), L18301. https://doi.org/10.1029/2011GL048677

Rolf, T., Coltice, N., and Tackley, P. J. (2012). Linking continental drift, plate tectonics and the thermal state of the Earth's mantle. Earth Planet. Sci. Lett., 351-352, 134-146. https://doi.org/10.1016/j.epsl.2012.07.011

Rolf, T., Capitanio, F. A., and Tackley, P. J. (2018). Constraints on mantle viscosity structure from continental drift histories in spherical mantle convection models. Tectonophysics, 746, 339-351. https://doi.org/10.1016/j.tecto.2017.04.031

Rozel, A., Ricard, Y., and Bercovici, D. (2011). A thermodynamically selfconsistent damage equation for grain size evolution during dynamic recrystallization. Geophys. J. Int., 184(2), 719-728. https://doi.org/10.1111/j.1365-246X.2010.04875.x

Rozel, A. B., Golabek, G. J., Jain, C., Tackley, P. J., and Gerya, T. (2017). Continental crust formation on early Earth controlled by intrusive magmatism. Nature, 545(7654), 332-335. https://doi.org/10.1038/nature22042

Shemenda, A. I. (1992). Horizontal lithosphere compression and subduction: constraints provided by physical modeling. J. Geophys. Res.: Solid Earth, 97(B7), 11097-11116. https://doi.org/10.1029/92JB00177

Sibson, R. H., and Rowland, J. V. (2003). Stress, fluid pressure and structural permeability in seismogenic crust, North Island, New Zealand. Geophys. J. Int., 154(2), 584-594. https://doi.org/10.1046/j.1365-246X.2003.01965.x

Sleep, N. H. (2000). Evolution of the mode of convection within terrestrial planets. J. Geophys. Res.: Planets, 105(E7), 17563-11578. https://doi.org/10.1029/2000JE001240

Sobolev, S. V., and Brown, M. (2019). Surface erosion events controlled the evolution of plate tectonics on Earth. Nature, 570(7759), 52-57. https://doi.org/10.1038/s41586-019-1258-4

Solomatov, V. S. (2004). Initiation of subduction by small-scale convection. J. Geophys. Res.: Solid Earth, 109(B1), B01412. https://doi.org/10.1029/2003JB002628

Stadler, G., Gurnis, M., Burstedde, C., Wilcox, L. C., Alisic, L., and Ghattas, O. (2010). The dynamics of plate tectonics and mantle flow: from local to global scales. Science, 329(5995), 1033-1038. https://doi.org/10.1126/science.1191223

Stein, C., Schmalzl, J., and Hansen, U. (2004). The effect of rheological parameters on plate behaviour in a self-consistent model of mantle convection. Phys. Earth Planet. Inter., 142(3-4), 225-255. https://doi.org/10.1016/j.pepi.2004.01.006

Stern, R. J. (2004). Subduction initiation: Spontaneous and induced. Earth Planet. Sci. Lett., 226(3-4), 275-292. https://doi.org/10.1016/j.epsl.2004.08.007

Stern, R. J. (2007). When and how did plate tectonics begin? Theoretical and empirical considerations. Chin. Sci. Bull., 52(5), 578-591. https://doi.org/10.1007/s11434-007-0073-8

Stern, R. J., and Gerya, T. (2018). Subduction initiation in nature and models: A review. Tectonophysics, 746, 173-198. https://doi.org/10.1016/j.tecto.2017.10.014

Stern, R. J., Gerya, T., and Tackley, P. J. (2018). Stagnant lid tectonics: Perspectives from silicate planets, dwarf planets, large moons, and large asteroids. Geosci. Front., 9(1), 103-119. https://doi.org/10.1016/j.gsf.2017.06.004

Tackley, P. J. (2000a). Self-consistent generation of tectonic plates in timedependent, three-dimensional mantle convection simulations 2. Strain weakening and asthenosphere. Geochem., Geophys., Geosyst., 1(8), $2000 \mathrm{G}$.
https://doi.org/10.1029/2000GC000043

Tackley, P J. (2000b). Self-consistent generation of tectonic plates in timedependent, three-dimensional mantle convection simulations 1. Pseudoplastic yielding. Geochem., Geophys., Geosyst., 1(1), $2000 \mathrm{G}$. https://doi.org/10.1029/2000GC000036

Tackley, P. J. (2000c). Mantle convection and plate tectonics: Toward an integrated physical and chemical theory. Science, 288(5473), 2002-2007. https://doi.org/10.1126/science.288.5473.2002

Tang, C. A., Webb, A. A. G., Moore, W. B., Wang, Y. Y., Ma, T. H., and Chen, T. T. (2020). Breaking Earth's shell into a global plate network. Nat. Commun., 11(1), 3621. https://doi.org/10.1038/s41467-020-17480-2

Tetreault, J. L., and Buiter, S. J. H. (2012). Geodynamic models of terrane accretion: Testing the fate of island arcs, oceanic plateaus, and continental fragments in subduction zones. J. Geophys. Res.: Solid Earth, 117(B8), B08403. https://doi.org/10.1029/2012JB009316

Thielmann, M., and Kaus, B. J. P. (2012). Shear heating induced lithosphericscale localization: Does it result in subduction?. Earth Planet. Sci. Lett., 359360, 1-13. https://doi.org/10.1016/j.epsl.2012.10.002

Toth, J., and Gurnis, M. (1998). Dynamics of subduction initiation at preexisting fault zones. J. Geophys. Res.: Solid Earth, 103(B8), 18053-18067. https://doi.org/10.1029/98JB01076

Turcotte, D., and Schubert, G. (2014). Geodynamics (3rd ed). Cambridge: Cambridge University Press.

Turcotte, D. L., and Schubert, G. (2002). Geodynamics (2nd ed.). Cambridge: Cambridge University Press.

Ueda, K., Gerya, T., and Sobolev, S. V. (2008). Subduction initiation by thermalchemical plumes: Numerical studies. Phys. Earth Planet. Inter., 171(1-4), 296-312. https://doi.org/10.1016/j.pepi.2008.06.032

Uppalapati, S., Rolf, T., Crameri, F., and Werner, S. C. (2020). Dynamics of lithospheric overturns and implications for Venus's surface. J. Geophys. Res.: Planets, 125(11), e2019JE006258. https://doi.org/10.1029/2019je006258

Uyeda, S., and Ben-Avraham, Z. (1972). Origin and development of the Philippine Sea. Nat. Phys. Sci., 240(104), 176-178. https://doi.org/10.1038/physci240176a0

van der Lee, S., Regenauer-Lieb, K., and Yuen, D. A. (2008). The role of water in connecting past and future episodes of subduction. Earth Planet. Sci. Lett., 273(1-2), 15-27. https://doi.org/10.1016/j.epsl.2008.04.041

van Hinsbergen, D. J. J., Peters, K., Maffione, M., Spakman, W., Guilmette, C., Thieulot, C., Plümper, O., Gürer, D., Brouwer, F. M.,... Kaymakcı, N. (2015). Dynamics of intraoceanic subduction initiation: 2 . Suprasubduction zone ophiolite formation and metamorphic sole exhumation in context of absolute plate motions. Geochem., Geophys., Geosyst., 16(6), 1771-1785. https://doi.org/10.1002/2015GC005745

van Hunen, J., and Moyen, J. F. (2012). Archean subduction: fact or fiction?. Annu. Rev. Earth Planet. Sci., 40, 195-219. https://doi.org/10.1146/annurevearth-042711-105255

Vogt, K., and Gerya, T. V. (2014). From oceanic plateaus to allochthonous terranes: Numerical modelling. Gondw. Res., 25(2), 494-508. https://doi.org/10.1016/j.gr.2012.11.002

von Hagke, C., Philippon, M., Avouac, J. P., and Gurnis, M. (2016). Origin and time evolution of subduction polarity reversal from plate kinematics of Southeast Asia. Geology, 44(8), 659-662. https://doi.org/10.1130/G37821.1

Wan, B., Wu, F. Y, Chen, L., Zhao, L., Liang, X. F., Xiao, W. J., and Zhu, R. X. (2019). Cyclical one-way continental rupture-drift in the Tethyan evolution: Subduction-driven plate tectonics. Science China Earth Sciences, 62, 2005-2016. https://doi.org/10.1007/s11430-019-9393-4

Watts, A. B., and Burov, E. B. (2003). Lithospheric strength and its relationship to the elastic and seismogenic layer thickness. Earth Planet. Sci. Lett., 213(1-2), 113-131. https://doi.org/10.1016/S0012-821X(03)00289-9

Wu, F. Y., Wan, B., Zhao, L., Xiao, W. J., and Zhu, R. X. (2020). Tethyan geodynamics. Acta Petrologica Sinica, 36, 1627-1674. (in Chinese with English abstract).

Yang, T., and Gurnis, M. (2016). Dynamic topography, gravity and the role of lateral viscosity variations from inversion of global mantle flow. Geophys. J. Int., 207(2), 1186-1202. https://doi.org/10.1093/gji/ggw335

Yin, A. (2012). An episodic slab-rollback model for the origin of the Tharsis rise 
on Mars: Implications for initiation of local plate subduction and final unification of a kinematically linked global plate-tectonic network on Earth. Lithosphere, 4(6), 553-593. https://doi.org/10.1130/L195.1

Zhang, N., Dang, Z., Huang, C., and Li, Z. X. (2018). The dominant driving force for supercontinent breakup: Plume push or subduction retreat?. Geosci. Front., 9(4), 997-1007. https://doi.org/10.1016/j.gsf.2018.01.010

Zheng, Y. F., and Chen, Y. X. (2016). Continental versus oceanic subduction zones. Natl. Sci. Rev., 3(4), 495-519. https://doi.org/10.1093/nsr/nww049

Zhong, S. J., and Gurnis, M. (1992). Viscous flow model of a subduction zone with a faulted lithosphere: long and short wavelength topography, gravity and geoid. Geophys. Res. Lett., 19(18), 1891-1894. https://doi.org/10.1029/92GL02142

Zhong, S. J., and Gurnis, M. (1995). Mantle convection with plates and mobile, faulted plate margins. Science, 267(5199), 838-843. https://doi.org/10.1126/science.267.5199.838

Zhong, S. J., and Gurnis, M. (1996). Interaction of weak faults and nonNewtonian rheology produces plate tectonics in a 3D model of mantle flow. Nature, 383(6597), 245-247. https://doi.org/10.1038/383245a0

Zhong, S. J., Gurnis, M., and Moresi, L. (1998). Role of faults, nonlinear rheology, and viscosity structure in generating plates from instantaneous mantle flow models. J. Geophys. Res.: Solid Earth, 103(B7), 15255-15268. https://doi.org/10.1029/98JB00605

Zhong, S. J., Zuber, M. T., Moresi, L., and Gurnis, M. (2000). Role of temperature- dependent viscosity and surface plates in spherical shell models of mantle convection. J. Geophys. Res.: Solid Earth, 105(B5), 11063-11082. https://doi.org/10.1029/2000JB900003

Zhong, S. J., Zhang, N., Li, Z. X., and Roberts, J. H. (2007). Supercontinent cycles, true polar wander, and very long-wavelength mantle convection. Earth Planet. Sci. Lett., 261(3-4), 551-564. https://doi.org/10.1016/j.epsl.2007.07.049

Zhong, X. Y., and Li, Z. H. (2019). Forced subduction initiation at passive continental margins: velocity-driven versus stress-driven. Geophys. Res. Lett., 46(20), 11054-11064. https://doi.org/10.1029/2019GL084022

Zhong, X. Y., and Li, Z. H. (2020). Subduction initiation during collision-induced subduction transference: numerical modeling and implications for the tethyan evolution. J. Geophys. Res.: Solid Earth, 125(2), e2019JB019288. https://doi.org/10.1029/2019JB019288

Zhou, X., Li, Z. H., Gerya, T. V., Stern, R. J., Xu, Z. Q., and Zhang, J. J. (2018). Subduction initiation dynamics along a transform fault control trench curvature and ophiolite ages. Geology, 46(7), 607-610. https://doi.org/10.1130/G40154.1

Zhou, X., Li, Z. H., Gerya, T. V., and Stern, R. J. (2020). Lateral propagationinduced subduction initiation at passive continental margins controlled by preexisting lithospheric weakness . Science Advances, 6(10), 1-10. https://doi.org/10.1126/sciadv.aaz1048 